\title{
Legitimidad y eficacia en la Administración pública
}

Manuel Arenilla Sáez*

Palabras clave: Administración Pública, legitimidad, eficacia, calidad de los servicios públicos, crisis del Estado de Bienestar, Nuevo Gestión Pública.

\section{Introducción}

Desde hace unas décadas se viene transformando el pensamiento tradicional sobre la Administración pública basado en el logro de la eficacia jurídica por otras corrientes que ponen su centro de atención en el logro de resultados o en el mejor manejo de los asuntos públicos y sociales. La nueva gestión pública, la búsqueda de la calidad, la gobernabilidad o el énfasis en los aspectos éticos alimentan las nuevas reflexiones sobre las instituciones públicas con el fin de que gocen de mayor legitimidad y aceptación por los ciudadanos. No se trata de verdaderos paradigmas explicativos de la realidad administrativa, sino de diversos enfoques que tratan de iluminar su enorme complejidad. Por eso conviven entre sí, se complementan, pero tampoco han logrado desplazar al pensamiento tradicional. Esto es debido a que sigue siendo válido como base para lograr la legitimidad y garantizar los derechos de los ciudadanos.

Las corrientes señaladas enfatizan en los resultados en la combinación de los diversos elementos del sistema político y de la sociedad para alcanzar una mayor gobernabilidad, pero no han cuestionado, al menos en la práctica, las instituciones políticas ni, más concretamente, el estilo de hacer política. De esta manera, la concreción práctica del pensamiento administrativo reciente se centra en el logro de la eficacia, entendiendo esta en un sentido amplio y no significativamente en la modificación, por ejemplo, de los sistemas electorales, del sistema de partidos o de los aspectos que tienen que ver con la representación. El nuevo pensamiento administrativo, aunque se dice preocupado por el ciudadano, sigue manteniendo realmente alejado al ciudadano del centro decisional, lo guarda cautivo de las decisiones de los poderes políticos, económicos, sociales o tecnológicos. No se ha logrado, así, relacionar de manera distinta al ciudadano con sus representantes, más allá de los ensayos neo-participativos y de los experimentos tecnológicos vinculados a la e-democracia.

* Catedrático de Ciencia Politica y de la Administración de la Universidad Rey Juan Carlos. 
La recepción del nuevo pensamiento administrativo en el caso español ha sido amplia aunque desigual y variablemente tardía. Podemos decir, en general, que se ha compartido la premisa de que el modelo formal burocrático de la Administración era el responsable de la falta de la eficacia de la misma y, también, del alejamiento de los ciudadanos de sus instituciones políticas y administrativas. Esto ha llevado a algunos, quizá ya hace un tiempo, a culpar al aparato administrativo y especialmente a sus integrantes, destacando a sus dirigentes profesionales, de los males de la Administración pública.

Los estudios recientes españoles sobre la Administración parten de una realidad que en muchos casos no es la nuestra. Suelen basarse también de una concepción homogénea de la Administración y de las Administraciones públicas que es inexistente. En fin, no es frecuente que entronquen con la rica y variada tradición de estudios sobre nuestra realidad administrativa.

La base del nuevo pensamiento sobre la Administración pública conduce, como se ha dicho, a la búsqueda de la eficacia de resultados y, claro es, estos hay que medirlos. De ahí que la plasmación práctica de las nuevas corrientes se concrete en la necesidad de evaluar lo que la Administración hace, en conocer las prioridades ciudadanas sobre las políticas públicas y, cada vez más, en la medición de la satisfacción ciudadana sobre el funcionamiento de los servicios públicos. Todo ello ha llevado a la realización de encuestas y estudios periódicos por las instituciones públicas, destacando sobre todas ellas el CIS. Además, no hay política nueva que se pretenda implantar o plan que se quiera redactar que no cuente con un variado despliegue de medidores de la realidad ciudadana y administrativa. Conocemos, por tanto, bastante bien qué es lo que dicen desear los ciudadanos de sus instituciones y tenemos datos suficientes para conocer el grado de aceptación de las mismas, incluso de forma detallada en algunos casos.

Los indicadores utilizados y las preguntas realizadas toman como fundamento teórico el nuevo pensamiento administrativo, aunque quizá en una versión simplificada que podría resumirse en que es necesario lograr la competitividad del aparato público, reforzar los cauces de participación ciudadana en el nivel de presentación de necesidades y conseguir la satisfacción del ciudadano al relacionarse con los distintos servicios públicos. Detrás de todo ello subyace la creencia, prácticamente aceptada por todos y por eso desideologizada, de que el funcionamiento del aparato público es más deficiente que el privado. Esto se ve reflejado de una manera clara en las distintas encuestas del CIS que se van a manejar en este trabajo.

Sin embargo, los medidores de la eficacia utilizados reflejan una realidad un tanto contumaz: se observa una mejora de los servicios, pero no una mayor legitimidad institucional ni una mayor aceptación de los dirigentes políticos, incluso si se toman en su acepción más amplia. Todo ello parece indicar, más allá del recurso simple a la existencia de un estereotipo social negativo sobre la Administración pública, que la legitimidad institucional no se logra sólo, pero sí necesariamente, con un mejor rendimiento del sistema político, sino especialmente con una manera distinta, algunos dirán que radicalmente distinta, de relacionar al ciudadano con sus dirigentes políticos.

En este trabajo se van a presentar las cuestiones anteriores con el fin de mostrar el pensamiento que subyace en la medición de la eficacia de las Administraciones públicas en nuestro país. El eje del estudio gira entorno a la premisa de que para lograr una mayor legitimidad institucional no basta con un mayor rendimiento sino que hay que abordar la actuación pública desde los referentes de actuación ciudadana. Estos referentes van más allá de lo que declaran los propios ciudadanos las encuestas. 


\section{El marco teórico. La legitimidad institucional y la de rendi- mientos}

\subsection{La legitimidad y el descontento}

\section{La crisis de la legitimidad política y las contradicciones de la Administración pública}

Desde hace tres décadas estamos asentados en lo que se ha venido en llamar la «crisis del Estado de Bienestar», incluso en aquellos países que nunca llegamos a disfrutar de este en su abundancia o no lo hicimos nada más que en algunos de sus aspectos. Este tiempo de crisis tiene ya la misma duración que el de la plena vigencia del Estado de Bienestar en los países que lo disfrutaron en toda su amplitud. Si hace unos años la literatura científica y los políticos se preguntaban por cuál sería el nuevo Estado que sustituiría al del Bienestar, la respuesta quizá pueda ser evidente: el que estamos viviendo en la actualidad.

Las causas de la crisis del «viejo» Estado suelen ser aceptadas por todos: en primer lugar, las financieras. Estas han ido evolucionando de unas iniciales derivadas de la crisis del petróleo de principios de los años setenta del siglo pasado a los duros programas de estabilidad presupuestaria o déficit cero impuestos por los organismos internacionales y, en nuestro caso, además, por las autoridades monetarias de la Unión Europea.

Lo cierto es que en nuestros días nos encontramos en el campo financiero, en resumen, con un pensamiento hegemónico que combina las viejas medidas de gasto social de integración de las minorías y de provisión de los bienes públicos esenciales, que son garantizados para todos los habitantes de un país desarrollado -no sólo para los ciudadanos en sentido estricto-, con otras medidas, que ahora son las dominantes, de contención del gasto y de prohibición del endeudamiento.

La dualidad anterior genera una tensión que tiene claras consecuencias sobre el quehacer de la Administración pública que intenta cumplir con su cometido de integración y articulación social, a la vez que trata de atender a los nuevos problemas y demandas sociales que coexisten con viejos problemas sociales no resueltos, todo ello con el menor gasto posible y in subir los impuestos. La solución que se ha buscado para resolver esta contradicción es el recurso, en algunos casos masivo, al sector privado, bien mediante la importación de sus valores, formas y técnicas de gestión, bien a través de la dación directa al mercado de algunos servicios, incluso los antaño considerados esenciales del Estado del Bienestar. El sustento teórico a esta solución se ha encontrado en los últimos tiempos en la nueva gestión pública. Además, la reducción del déficit o el incremento de los recursos financieros se logran también mediante la venta de activos públicos. Esto sucede tanto en los gobiernos de corte conservador como socialdemócrata.

La segunda causa de la crisis del viejo modelo sobre el que descansaba el Estado de Bienestar es la llamada «pérdida de valores». Realmente habría que decir la «pérdida de los valores tradicionales» por los que nos regimos durante décadas, ya que han ido sustituyéndose por otros. Lo que está en crisis es el desarrollo ilimitado, la garantía de la riqueza y el bienestar vinculados a los constantes descubrimientos científicos y tecnológicos, la existencia de un interés general, la posibilidad de conseguir una sociedad sin desigualdades o la trascendencia humana en sus más variadas formas filosóficas, ideológicas o religiosas. Podemos concluir que nos hallamos instalados en una cultura de la apatía caracterizada por la existencia de unas fronteras porosas y por unas prescripciones severas para los ciudadanos (Wildavsky 1987: 285; Frías 2001: 181). 
Ante este nuevo modelo cultural, las instituciones políticas y administrativas han tratado de responder con una cesta de medidas. En la cultura, como a veces en la medicina, parece que ya no basta con un medicamento específico, sino con una combinación de fármacos que tratan de atacar tanto el origen de una enfermedad, muchas veces desconocido, como los destrozos producidos en los distintos sistemas del organismo. La cesta está compuesta por medidas de tipo solidario-participativo con otras de corte liberal-competitivo. Se complementan las viejas medidas paternalistas con otras en las que se incluye la participación, que ya resulta imprescindible para apuntalar la legitimidad del sistema democrático y para que sean aceptadas muchas de las actuaciones públicas.

Una evidencia del cambio cultural se puede observar en la evolución misma de la participación. Por un lado, sigue dominando la concepción moral frente a la racional-utilitarista, aunque ésta no es desdeñable y es probable que esté creciendo, pero, por otro lado, la lógica que vence en la moral ya no es religiosa, sino cívica (Pérez 2002)

Pero quizá el cambio esencial para lo público en estos últimos años provenga de la propia posición del ciudadano respecto de sus instituciones políticas y administrativas. En una suerte de evolución, se ha pasado de un ciudadano/administrado a otro usuario/cliente, y de aquí a otro ciudadano-democrático que desea no ser un mero espectador del juego desarrollado entre los poderosos de la sociedad, sino que la desea «co-conforman», desea establecer él mismo las reglas del juego como un participante activo. Es cierto que en este último rol no podemos situar a la mayoría de los ciudadanos y que siempre estamos hablando de unos ciudadanos que tienen cubiertas sus necesidades vitales, sociales y relacionales, pero lo cierto es que la tendencia señalada parece plausible puesto que se constata un ciudadano cada vez más exigente con sus instituciones públicas (CIS 2000. Estudio 2.394).

Los efectos de este cambio cultural para la Administración pública han sido ciertamente devastadores. Ésta ya no es la única que interpreta, a veces muy discrecionalmente, el interés general, que ya ha pasado descarnadamente a estar conformado por una serie de intereses privados hechos públicos por el poder. El nuevo papel de la Administración es el de otorgador del marchamo de legitimidad a los participantes-conformadores de las reglas públicas a la vez que «arena» en la que interactúan los diversos participantes. Pero también es el «botín» de esos participantes, ya que la participación tiene su sentido y meta en la intervención en el proceso de las políticas públicas y en los beneficios directos que obtienen con ello los diversos participantes.

La tercera causa de la crisis de la Administración pública se refiere específicamente a los problemas que plantea la transmisión de la decisión política al nivel de su ejecución por la Administración pública. Ya no es posible pensar que un conjunto de iniciativas políticas encuadradas en un determinado pensamiento político, más o menos coordinadas entre sí, que satisfagan a un colectivo variablemente amplio y que además sean ejecutadas con acierto, sea suficiente para lograr el consentimiento de los ciudadanos (Baena 2000: 107). Por ello se trata de buscar su aceptación mediante técnicas que hagan posible conocer sus preferencias y su evaluación de los servicios públicos. Es precisamente esta evaluación la que otorga el éxito o el fracaso de la gestión, aunque la última palabra la siguen teniendo las elecciones. Se pone así el énfasis en los resultados y se destaca la condición de cliente del ciudadano que, como en la empresa privada, «siempre lleva la razón».

La orientación de las decisiones de las políticas públicas se pasa a determinar en parte por la opinión declarada de los ciudadanos. Mediante sus opiniones se establecen nuevos referentes de actuación y de gasto público que son adoptados por los decisores públicos. Esto puede hacer pensar en un «gobierno por encuestas». Se relega, o al menos existe un alto riesgo de que esto suceda, la política en beneficio de la gestión, se posponen las decisiones estructurales de la sociedad en beneficio del predominio de lo «micro». La política se asemeja cada vez más a un servomecanismo en el que, una vez adoptada una decisión y contrastada su eficacia en la validación declarada por el ciudadano, se vuelve a reconsiderar la decisión política. 
El modelo de evaluación descansa en que los intereses declarados por el ciudadano son realmente los operativos, aquellos por los que realmente se rige y actúa el ciudadano, y que no están «contaminados» por la intencionalidad del evaluador de la calidad o por lo que es políticamente correcto declarar en cada momento. También se parte, y esto es más arriesgado, de que lo declarado por el ciudadano es trasladable sin más al ámbito de la decisión política. Esta forma de actuar arroja frecuentemente no pocas sorpresas como podemos comprobar en los constantes cambios en algunas políticas públicas.

El recurso al ciudadano-cliente como validador de la acción pública no evita las contradicciones entre decisión y ejecución y hace que aparezcan otras. La Administración pasa a ser gestora de las contradicciones que ocurren en su interior y alrededor de ella, algo que no era extraño anteriormente, solo que ahora las discrepancias afectan a los referentes de actuación y no tanto al empleo de los medios o al predominio de unos grupos burocráticos sobre otros, como era lo habitual.

A la Administración se la mide por sus resultados y estos toman preferentemente como referencia los propios del sector privado comercial, que es lo que declara el ciudadano que se haga cuando se le pregunta al respecto. La consecuencia de esto es que se sustituye la legitimidad legal-racional por otra basada en una decisión política que se espera que goce de la aceptación de los ciudadanos porque se considera que es la suya. Subyace en esta sustitución la idea equivocada de que la Administración legal-racional es menos democrática que la que se basa en los resultados (Beltrán 2000: 190).

La contradicción de la Administración en este caso es que está sometida al imperio de la ley, la fuente última de su legitimidad ciudadana, pero a la vez se le exige buscar preferentemente los resultados declarados por los ciudadanos. El énfasis en la legitimidad de rendimientos es cierto que sitúa a la Administración en el centro del debate político, pero en este ella aparece como impedimento, al menos parcialmente, de la consecución de la legitimidad institucional. De ahí se deriva que para conseguir esos resultados se prescinda en muchas ocasiones de la organización que inicialmente era la encargada de lograrlos. La creación de un ingente aparato para-público bajo formas societarias privadas o casi privadas y los conciertos con el sector no comercial son la solución que se ha adoptado generalmente para superar la contradicción apuntada y no la reforma de la Administración pública, ya que se ha considerado que ésta no tiene arreglo, que puede demorarse excesivamente en el tiempo y que los altos responsables de la gestión pública pueden obtener poca rentabilidad en sus carreras si dedican las energías necesarias a ese empeño.

Las tres causas de las crisis de la Administración pública están relacionadas. La primera de ellas, la financiera, ha sido la desencadenante y ha activado la transformación del sistema económico que ha incidido en el político y en el cultural (Baena 2000: 106). La Administración pública, integrante del sistema político institucional, ha sido la encargada de transmitir los nuevos valores a la sociedad, además de experimentar un profundo cambio para adaptarse a los nuevos requerimientos que de ella se demandan.

Las instituciones públicas presentan una acusada falta de legitimidad, aunque se constate por los ciudadanos que sus resultados son cada vez mejores y que los decisores públicos parezcan alinear sus iniciativas con los deseos expresados por los ciudadanos. Los relativamente frecuentes casos de corrupción, la percepción ciudadana de que el hacer político está regido por los imperativos vinculados por el poder (CIS 1994: 50) y, especialmente, que los ciudadanos no perciban de forma directa cuál es el impacto global de su participación en el juego democrático (Frías 2001: 181) cimentan sólidamente la pérdida de legitimidad de las instituciones públicas. Por eso extraña que se enfatice en la división entre legitimidad institucional y la de rendimientos cuando el origen de las dos está en la misma validación ciudadana. 
El ciudadano, al rechazar, al menos con cierta intensidad, a las instituciones que ejercen el poder sobre él, también lo hace sobre las Administraciones públicas que le prestan los servicios. Cosa distinta es que, preguntado el ciudadano sobre la valoración de los servicios públicos, los puntúe cada vez mejor. Los rendimientos son condición necesaria para otorgar la validación ciudadana a las instituciones públicas, pero no suficiente. Esto es debido a que el origen del problema de la legitimidad es de naturaleza política y no de eficacia administrativa y remite al consentimiento de la dominación que ejerce el poder público sobre los ciudadanos.

La Administración se enfrenta al reto de lograr una mayor legitimidad institucional mal pertrechada, ya que tiene que superar, al menos, las siguientes asimetrías:

- Garantizar la cohesión social, lo que implica incrementar las políticas de gasto, y lograr la contención del gasto público.

- Responsabilizarse de la aceptación social de los nuevos cambios culturales y compartir su consecución con una serie de agentes que pueden no responsabilizarse de los resultados.

- Legitimarse por el cumplimiento de la ley o por los resultados.

En las páginas que siguen trataremos de profundizar en las asimetrías anteriores desde la perspectiva seguida por las instituciones políticas españolas para lograr el consentimiento ciudadano, la satisfacción política, la afección y la legitimidad institucional y de resultados.

\section{Legitimidad y cambio en las instituciones públicas}

A pesar de los fuertes cambios experimentados en todos los órdenes, y también en la Administración pública, las instituciones políticas apenas han modificado su configuración. Nos podríamos benévolamente preguntar con Dahl: «ino podría ser que nosotros, como los romanos, seamos insuficientemente creativos a la hora de reorganizar nuestras instituciones políticas?» (1999: 21), aunque quizá la clave esté en plantear qué es lo que hay de ganancia en las pérdidas de legitimidad experimentadas por las instituciones políticas. Es decir, las instituciones deben experimentar en la actualidad una serie de beneficios que hagan que sus dirigentes no estén dispuestos a introducir cambios sustanciales que pongan en peligro sus ganancias.

No es objeto de esta investigación seguir por estos derroteros; baste apuntar que algunos políticos no desean satisfacer las demandas de los ciudadanos manifestadas en diversos estudios sobre un nuevo estilo de hacer política que se resumiría en (González 2001):

- planificar las actuaciones públicas;

- ser experto en su área de actuación;

- informar al contribuyente del destino de los fondos públicos;

- regular eficazmente las ayudas con dinero público;

- reducir el gasto ordinario;

- tener capacidad de gestión y asumir riesgos;

- ser evaluado, y que se le exijan responsabilidades.

La negativa a afrontar estos cambios apunta a una conformación del poder político centrada en los intereses de los partidos políticos y los de los grupos poderosos, que se encuentra alejada de los ciudadanos y de sus organizaciones más próximas (Frías 2001: 181), lo que genera el extrañamiento democrático de los ciudadanos y la pérdida de la legitimidad de las instituciones. 
Este extrañamiento no afecta sólo a los políticos y a los altos responsables de la gestión pública, sino que a ellos se han añadido otros grupos de poderosos. Este sería, por ejemplo, el caso de los medios de comunicación. Para una parte de los españoles, la existencia de un sistema político-informativo les genera desconfianza y apatía y se sienten ante él inermes, ya que perciben su importancia pero no pueden controlar sus efectos (Jerez, Sampedro y Baer 2000: 120-1).

Si es posible que no seamos creativos en la adaptación de nuestras instituciones políticas, no es el caso de las administrativas. En esta cuestión sí se escucha la opinión del ciudadano a través de numerosas encuestas en las que declara saber cómo reformar la Administración y por qué referentes debe regirse su gestión. Podría pensarse que el énfasis en la legitimidad de resultados y en la incorporación de planteamientos del estilo de la nueva gestión pública o la calidad trata de evitar que se entre en el fondo de la cuestión que no es otra que el agotamiento de ciertas instituciones políticas y del estilo de gobernar los asuntos públicos.

El logro de la legitimidad institucional ha estado cifrado en tener éxito en la selección de los intereses sociales y sus representantes, en saber lo que opinaban con la mayor precisión posible los ciudadanos, en lograr una participación lo más transparente posible y conseguir educar en los valores y prácticas democráticas a los ciudadanos (Font 2001: 225). Sin embargo, estas medidas no han logrado evitar el constante desprestigio de las instituciones y la percepción ciudadana de que el poder es ejercido descarnadamente por una serie de grupos que imponen sus intereses sobre el resto.

Obsérvese que se ha utilizado en varias ocasiones el término percepción. Se enfatiza así en los aspectos no racionales de la actuación ciudadana, pero unos aspectos que en la mente del ciudadano actúan como construcciones reales, como «cosas» tan reales como los servicios que se prestan. Sin embargo, se aprecian esas percepciones cuando sirven para medir la calidad de los servicios públicos, pero no para valorar la legitimidad de las instituciones que los prestan. Esta desigualdad es la expresión de otra más profunda que separa los referentes de verificación que los ciudadanos esperan de los poderes públicos de los referentes que poseen los altos responsables de la gestión pública de cada institución. Este alejamiento se hace más patente en el nivel autonómico y estatal que en el local, donde el ciudadano percibe una Administración más cercana a sus necesidades y expectativas (CIS 2000. Estudio 2.387). No hay que olvidar que las expectativas, junto con la responsabilidad asignada a cada nivel gubernamental sobre los resultados alcanzados, son las determinantes explicativas del voto (Sánchez y Barreiro 2000: 85). Se puede decir, para concluir, que la percepción de legitimidad es una de las claves de la buena gobernabilidad.

El único cambio de cierto calado realizado en las instituciones políticas es la introducción más o menos generalizada de la participación en las diversas fases de las políticas públicas, aunque es más fácil hallarla en la implementación, especialmente en el nivel de ejecución, que en la fase de la adopción de decisiones. También es variable el tipo de participación. Suele dominar la de carácter neocorporativo y en esto hay pocas diferencias con el modelo participativo clásico del Estado de Bienestar. Lo que ha sucedido es que se ha extendido esta modalidad de forma imparable a casi todos los órdenes de la actuación pública. Sin embargo, este tipo de participación puede reforzar en el ciudadano el sentimiento de alienación del poder al manifestar una credibilidad equiparable para los partidos políticos, sindicatos y organizaciones empresariales y sus representantes (CIS 1999. Estudio 2.364), que son los actores integrantes esenciales de la participación neocorporativa.

Junto a este tipo de participación han aparecido otra serie de modalidades que se superponen a la anterior que es la que ha logrado un amplio grado de institucionalización y de extensión. Así, podemos encontrar diversos niveles que van desde la obtención de información hasta la codecisión, pasando por la teledemocracia o los 
presupuestos participativos. Hay que señalar que la superación de una participación de carácter neocorporativo no depende tanto de los mecanismos de participación, sino esencialmente de la apertura a otros agentes sociales distintos de los sindicatos, organizaciones empresariales y algunas otras organizaciones «clásicas».

Lo cierto es que la participación entendida bajo las nuevas modalidades no está extendida en las instituciones políticas españolas, aunque podemos encontrarla de forma muy desigual en el ámbito local. Además, la literatura científica señalaba que no parecía detectarse una reivindicación intensa de profundización en la democracia local (Botella 1999: 216) y que los estudios sobre cultura política mostraban a unos españoles no demasiado participativos (Frías 2001: 179; CIS 2000. Estudio 2.387. CIS 2001. Estudio 2.419).

Hay que señalar que a pesar de la amplia difusión de los casos de participación no existen indicadores que permitan medir los posibles cambios que se han podido producir en las instituciones que han adoptado experiencias de participación, ni tampoco es posible comparar los diversos casos existentes. No obstante, el conocimiento que se tiene de las experiencias existentes sobre las nuevas modalidades de participación no permite señalar que se hayan conjurado algunos males de la vieja participación.

Es evidente que sigue dominando la lógica de partido sobre la participativa, e incluso se puede aventurar que esa lógica puede determinar la inclusión de los intereses y de los grupos llamados a participar. Además, la participación afecta «a los de siempre», sea cual fuere la modalidad empleada (Vilas 2000: 10). También se puede inferir que en muchos casos los partidos políticos pueden utilizar las organizaciones sociales como «cantera» de nuevos líderes o candidatos electorales y como mecanismo de control social. Esta situación no significa que la nueva participación esté llamada a fracasar, pero sí que la mera introducción de medidas participativas, aunque sea mediante instrumentos normativos, no garantiza por sí sola el cambio cultural que se precisa para pasar de un modelo orientado a las necesidades de los partidos y de sus dirigentes a otro en el que se tengan más en cuenta las necesidades de los ciudadanos.

Las anteriores cuestiones no son las únicas dificultades a las que se enfrenta la participación. La más importante es la que la contrapone a la representación, por lo que podríamos preguntarnos si la generalización de los instrumentos participativos no violaría algunos de los principios básicos en que se asientan las democracias representativas (Font 2001: 233-5). Por otra parte, cuestiona la manera en la que los partidos políticos van a poder plantear proyectos globales, en el ámbito de que se trate, si los ciudadanos pueden optar por proyectos no compartidos por el equipo de gobierno. Estas cuestiones remiten claramente al principio de responsabilidad.

Llegado el caso podría darse la situación en la que los equipos de gobierno, por ejemplo municipales, fueran simples gestores de las decisiones sometidas a los ciudadanos. Cabe preguntarse entonces cuál sería el criterio de elección de los representantes políticos, si servirían de algo los programas políticos o si la ideología tendría peso en el voto. En un modelo radical, que no parece ni mucho menos cercano, la teledemocracia haría que se adoptaran decisiones instantáneas y probablemente contradictorias. En este panorama es fácil plantearse el futuro del actual sistema de partidos o de las mismas elecciones Además, quedaría la cuestión central de la representatividad. ¿Hasta qué punto se sentiría el ciudadano individual responsable de múltiples decisiones colectivas manifestadas a través de su opción, por ejemplo, en distintos referenda? ¿Qué le impediría adoptar decisiones contradictorias con otras previamente tomadas? ¿Qué castigo recibiría si así lo hiciese? Estas preguntas pueden plantearse también sin llegar a la modalidad participativa del referéndum o de la teledemocracia generalizada, si se realizan sobre las más comunes modalidades de consulta o incluso codecisión en las que participan determinados grupos de interés. 
Por otra parte, los integrantes de los procesos participativos lo son a favor o en contra de algo o de alguien, de ahí que las nuevas formas participativas no eliminan el sesgo «partisano» de las decisiones (Lindblom 1990: 265) y este hecho agrava los problemas de responsabilidad de los nuevos decisores. El pretendido refuerzo de la democracia por la participación puede llevar, por tanto, el germen de un cambio de modelo de democracia y esto no parece demostrado que lo desee la gran mayoría de los ciudadanos.

En fin, la participación produce también un efecto que se ha llamado cautividad. En esta situación se encuentran los dirigidos de las corporaciones enmudecidos por sus dirigentes y los ciudadanos no afiliados o no integrados en las corporaciones. La regla es que a mayor grado de corporativización se suelen producir más número de cautivos (García de la Cruz 1995: 46-7). La extensión de la participación tiene que luchar con la percepción de cautividad de los ciudadanos. Los no cautivos suelen achacar a los demás la culpa de su situación, ya que desde su posición todo el mundo puede acceder a participar, incluso se llega a hablar de la existencia de un déficit de socialización política que se manifiesta en la escasez de ciudadanos «apropiados para la democracia» (Dienel y Harms 2000: 22).

Si la legitimidad tiene importancia es porque en los sistemas políticos democráticos es el fundamento de la existencia misma de la democracia. Su refuerzo se suele realizar mediante la participación y la descentralización, en el ámbito institucional, y en el de la eficacia, por la legitimidad de resultados. La descentralización no se plantea sólo desde el punto de vista territorial, aunque ésta es evidente en los países de nuestro entorno, sino también en lo que se ha venido en llamar devolución del poder a las personas.

Se parte de que los partidos políticos, los poderes públicos y las organizaciones afines han acumulado un gran poder que es lo que ha generado en gran medida la deslegitimación del poder político (Frías 2001: 181), por lo que procede ahora reintegrarlo, descentralizarlo, a los ciudadanos y a sus grupos organizados. Tanta generosidad por parte de los poderosos puede hacer sospechar si en realidad no se trata de un acto de impotencia que lleve a compartir la responsabilidad con el ciudadano o sus grupos por la falta de legitimidad del sistema político. Además, cabe preguntarse si el ciudadano corriente, «el cautivo», siente realmente esa necesidad y si desea formalizar un nuevo contrato social con sus dirigentes por el que éstos pasen a tener menos responsabilidades y ellos más. Para muchos ciudadanos el poder público, a pesar de todo, sigue siendo el único garante de su integración e incluso subsistencia social. En un proceso de devolución o de amplia participación no parece que los actualmente excluidos del sistema o que habitan en sus fronteras vayan a tener más oportunidades que en la actualidad, o al menos este extremo no se ha aclarado lo suficiente.

Por último, los cambios tecnológicos no pueden ser tomados como la gran esperanza para la democracia, ya que «ninguno de los cambios tecnológicos producidos fueron por sí mismos una fuerza conductora o determinante para los cambios positivos» (Gualteri 1999). Todo parece indicar que las esperanzas hay que ponerlas en los cambios sociales y culturales, en las prioridades de los gobiernos, en la voluntad política y en la estructura de las instituciones. Ello exige fuertes aportes de input público en el proceso de las políticas públicas (Gualteri 1999), precisamente en un momento histórico en que todo parece apuntar en otra dirección.

\section{Eficacia, calidad y legitimidad}

El logro de la legitimidad ha puesto énfasis en el rendimiento del sistema político. Esto ha dado lugar a la entrada en el mundo público de los enfoques y técnicas propios del sector privado orientados a la consecución de la eficacia-eficiencia y de la calidad. Los enfoques gerencialistas, en sus más diversas formas e intensidades, 
han producido una relativización de la política y han puesto el énfasis en el individuo que se ha convertido, no en el referente de la gestión pública, sino en el responsable del éxito de las decisiones adoptadas, a través de la medición de su reacción ante las diversas actuaciones públicas.

Los nuevos enfoques y técnicas eluden, en general, entrar en el funcionamiento del aparato administrativo y en la ordenación e interrelación de sus medios. Se corre así el riesgo de perder la visión global de la Administración pública y, lo que quizá sea más delicado, la misión que tiene en el sistema político y en la sociedad. Además, podemos observar en la actualidad la cada vez mayor fragmentación del aparato público, lo que dificulta la asignación de responsabilidades a los decidores públicos por parte de los ciudadanos, que no clientes.

\section{La mejora del rendimiento y la legitimidad}

La eficacia en los resultados, que no en el procedimiento, la eficiencia y la calidad se convierten en los referentes de actuación pública con el fin de lograr su legitimidad. No se trata de contraponer estos nuevos valores a la garantía de las libertades, ya que el logro de unos buenos resultados debe ejercerse respetando las libertades (Baena 2000: 43). Tampoco se quiere decir que la preocupación por la eficacia o la eficiencia responda a una ideología privatista, ya que en sí misma es un desarrollo del Estado de Bienestar al vincularse a la noción de legitimidad (Beltrán 2000: 59). No hay que olvidar que la segunda cualidad más valorada en los líderes de los países de nuestro entorno es la eficacia (Kaufmann 1997: 176).

De todo ello se observa una despolitización de la gestión pública que puede hacer que el ciudadano, bajo la forma de cliente, puede sentirse más indefenso que bajo el viejo modelo de autoridad. Así se puede decir que el cliente insatisfecho puede considerarse peor tratado y más alienado (Olías de Lima 2001: 27) y que su descontento, a diferencia de lo que ocurre en la empresa privada, no se dirija solamente a los responsables directos o a la organización prestataria del servicio, sino directamente al último responsable que no puede ser otro que el Gobierno. De nuevo por los resultados volvemos a las instituciones, en este caso mediante la insatisfacción política y el ejercicio del voto, aunque muy bien puede devenir en desafección política y, por tanto, en alejamiento del sistema político o incluso en un cuestionamiento de la legitimidad democrática. Si hacemos un símil con el sector comercial, sería como si un cliente insatisfecho con la prestación de un servicio privado llegase escalonadamente con su insatisfacción a cuestionar el mercado y obrara en consecuencia.

A la Administración pública se le exige eficacia con el fin de que aporte legitimidad al sistema político. En realidad se le está pidiendo un imposible, o al menos algo que no depende principalmente de ella. En un apartado anterior hemos visto las contradicciones estructurales a las que la Administración tiene que atender. El logro de la cohesión social se presenta como un fin básico del Estado para su supervivencia, pero ello debe lograrse en medio de fuertes restricciones presupuestarias y de demandas constantes por parte de los ciudadanos y de los grupos organizados. La transmisión a la sociedad de los valores y de las decisiones adoptados por el poder y concretados en el Gobierno experimenta un gran número de interferencias y de posibles errores, no siendo el menor que las decisiones adoptadas no hayan previsto adecuadamente los medios necesarios para que se ejecuten eficazmente.

Bien sea la misión de la Administración pública tratar de resolver las contradicciones del sistema de producción capitalista (Offe 1984: 35), bien sea lograr una mayor legitimidad de resultados que redunde en una mejor legitimidad institucional, el asunto de la eficacia aparece como central en la actuación administrativa. Pero, claro es, no se trata de cualquier tipo de eficacia. No basta que la Administración pública se dirija a satisfacer las fun- 
ciones básicas del gobierno o de las leyes, sino que es preciso que realice actividades que sean un beneficio concreto para la comunidad (Baena 2000: 282), incluso, y más en nuestros tiempos, para los individuos. Este tipo de eficacia nos remite al concepto de eficacia social (D’Amico 1992: 404).

La eficacia se busca para llegar a la legitimidad y una forma de lograrla es mediante la prelación de las políticas públicas, atendiendo a las preferencias de los actores que intervienen en la toma de decisiones y en la propia opinión ciudadana. La cuestión de la asignación presupuestaria a las políticas concretas no está sólo relacionada con la eficacia, sino con la legitimidad del destino mismo de los fondos públicos. Esto es lo que lleva a decir que existe una consideración moral del gasto público que entrelaza la eficacia del Estado con su legitimidad (De Miguel y De Miguel 2001: 63). Esta consideración moral se relacionaría con los conceptos de eficiencia social manejados por D’Amico y unas inversiones públicas productivas, «efectivas socialmente» y que se gestionen los fondos públicos «con utilidad social» (González 2001: 64). No hacerlo, o no transmitirlo, lleva a que el ciudadano perciba, en ocasiones sin justificación, que el gobierno despilfarra gran parte de sus impuestos (De Miguel y De Miguel 2001: 81), a pesar de declararse cada vez más satisfechos con el funcionamiento de los servicios. En definitiva, de lo que se trata es de alinear los referentes de verificación de las políticas públicas con los referentes de los ciudadanos. No hacerlo supone un claro desgaste para la legitimidad del sistema político.

La eficacia está estrechamente ligada a la viabilidad de la decisión pública y a la capacidad gerencial de la Administración pública y de sus responsables y empleados públicos. Se trata de lograr una adecuada combinación de las funciones administrativas, los tipos de actividad que realiza, con los factores administrativos, los medios que la organización tiene a su alcance y, además, que esto se realice en cada una de las fases de las políticas públicas. De no hacerse así nos encontraremos con políticas idealistas o meras declaraciones políticas más o menos bien intencionadas. Se precisa, por tanto, en la fase de adopción de decisiones que se hagan las previsiones adecuadas para que se presten adecuadamente los servicios (Baena 2000: 284).

Cabría realizar una advertencia sobre la eficacia y su referencia como medio para incrementar la legitimidad de las instituciones y el apoyo al gobierno de turno. El logro de la eficacia de los servicios públicos es una condición necesaria, una obligación que tienen contraída los responsables de la gestión pública con los ciudadanos. Los ciudadanos se creen con derecho a que los poderes públicos actúen con eficacia; por eso, ésta no basta para otorgar la legitimidad institucional. Esta es una de sus debilidades, por lo que destinar a ella la mayor parte de la energía política disponible sólo garantiza el reconocimiento de una labor que ya se espera como consecuencia del pago de los impuestos. También es cierto que un gobierno ineficaz es, en nuestro contexto actual, rechazado por los ciudadanos.

La debilidad de la eficacia como referente exclusivo de actuación también se observa en los casos de corrupción (Sánchez-Cuenca y Barreiro 2000: 85) o en un caso muy grave de mal funcionamiento de un servicio. La forma en la que se enfrenten los gobiernos a estos casos hace que ya no podamos hablar sólo de un nivel en el que los ciudadanos tienen preferentemente en cuenta los resultados, sino también de otro nivel en el que los ciudadanos actúan teniendo en cuenta fundamentalmente sus sentimientos sobre sus dirigentes e instituciones, y provoca que se pueda producir desafección política, pérdida de legitimidad institucional y, llegado el caso, pérdida de adhesión a la democracia.

\section{El logro de la legitimidad por la satisfacción del cliente}

La calidad surge en el sector privado comercial y trata de reforzar la competitividad. La calidad responde a la necesidad generada por la profunda interconexión entre las empresas privadas que ha venido reforzada por la 
gran diversificación empresarial y por tendencias como el outsourcing. Se han establecido una serie de redes que enlazan desde procesos decisionales hasta los suministros necesarios para la producción. Se puede decir que la calidad es una nueva lengua franca de la globalización económica necesaria para homologar de forma segura y fiable las relaciones entre las empresas. El sello de calidad certifica la fiabilidad de los intercambios, lo que redunda en la competitividad y en el beneficio, minimizando los costes de transacción.

Pero la calidad también ha reorientado los objetivos empresariales al introducir un cambio que puede denominarse estratégico. Se ha pasado de fabricar productos a satisfacer individuos. Es decir, lo que cuenta ahora es lo que percibe el consumidor (Lloréns 2000: 23). Los clientes pasan a ser el elemento clave del proceso de innovación, y sus necesidades, no las de la empresa, predominan en dicho proceso. Con dicha innovación se trata de acortar el tiempo de satisfacción del cliente y de adelantarse a sus propias necesidades futuras.

La importación de la calidad al sector público ha sido desigual y no ha sido muy tratada en la literatura más allá de la descripción de las técnicas que la acompañan. Ha tenido un éxito relativo en las unidades «industrializadas» y, por tanto, equiparables a sus homólogas del sector privado. En algunos casos (laboratorios y centros certificadores en procesos industriales o de consumo), ha venido impuesta por la normativa europea e internacional como consecuencia de que forman parte importante de las redes de producción e intercambio. En otros, se ha tratado de aproximar a los criterios propios del sector comercial con el fin de mejorar la imagen ante los ciudadanos. Esto ha sucedido especialmente en aquellas áreas cuya misión es relacionarse directamente con las empresas privadas. Normalmente, en estos casos se trata de organizaciones diferenciadas bajo la forma de agencias o sociedades mercantiles públicas y que, por tanto, ya comparten una serie de elementos culturales propios del sector privado. En las demás, nos encontramos ante más o menos calculadas operaciones de marketing. Conviene anotar que la introducción de la calidad ha arrinconado en muchos casos los procesos de modernización administrativa que podríamos denominar «clásicos», esto es, se han relegado, o simplemente sustituido, las reformas de los medios administrativos o al menos ya no se abordan de una manera global o integral.

La introducción de la calidad en la Administración pública, como suele suceder con diversas formas de gestión, técnicas o valores provenientes del sector privado, es habitual que se realice sin tener en cuenta el principio de contingencia. Éste nos habla de los aspectos culturales y, así, se puede afirmar que cambiar el referente organizacional, del procedimiento normativo a la satisfacción del cliente, no significa que nos movamos en el ámbito cultural completo en el que surge el concepto de calidad. Pero esto tampoco sucede automáticamente en el ámbito privado.

Castresana y Blanco nos dirán (2000: 14 y ss.) que implantar, por ejemplo, los círculos de calidad en una empresa española puede resultar frustrante e incluso contraproducente porque pueden chocar frontalmente con su propia cultura. Apuntan certeramente que para la implantación de cualquier innovación es preciso realizar cambios coherentes en otros elementos del sistema de que se trate, como en la selección de personal, la formación, el control, etc. Si se realizan cambios aislados, la cultura organizacional puede impedir, por ejemplo, que arraigue la calidad. Concluyen con algo que puede sonar paradójico en los tiempos que corren: «Hemos de ser conscientes de que es mejor dirigir apoyándose en la cultura vigente que pretender cambiarla; las creencias y valores de las organizaciones prevalecen durante años» (2001: 15).

Para introducir cualquier innovación, por tanto, hay que contar con la realidad que existe en un momento determinado y armarse de paciencia. Esto exige un fuerte liderazgo que no es otra cosa que lo que Peters señala como «persistencia pura» u «obsesión» (Parrado 2001: 156). Lo que ocurre es que el tiempo político, tan necesitado de éxitos a corto plazo, no suele coincidir con el tiempo de las organizaciones. 
El enfoque de la calidad tiene de positivo la reorientación de los objetivos de la actuación administrativa. La Administración pública debe ahora seducir a su público que tiene una dimensión más amplia que la de cliente, porque un ciudadano que paga sus impuestos no puede subsumirse en tal categoría (Baena 2000: 122). El concepto de cliente hace girar el foco del interés de la acción pública hacia un individuo que parece que recibe servicios en régimen de rivalidad y exclusión, lo que es propio de los bienes privados (Meunier 1993: 41).

En realidad, la categoría de ciudadano es mucho más amplia que la de cliente, no sólo porque en numerosas ocasiones es simplemente un sujeto sometido al dominio de la Administración, sino porque puede estar interesado en la prestación de servicios de los que él no se aprovecha, bien porque no pueda, bien porque no le interese o no esté en condiciones de necesitarlos. El concepto de cliente limita la naturaleza política de un sujeto social y relacional preocupado por la marcha de la sociedad en la que vive. Esta podría ser la principal crítica a la introducción aislada de la calidad en el ámbito público.

Una segunda crítica provendría del establecimiento de objetivos de calidad. Su medición a través de indicadores y su comparación con estándares es probable que oriente a los empleados de las organizaciones a cumplir dichos estándares más que a satisfacer a los individuos (Olías de Lima 2001: 27). El énfasis recaería en el cumplimiento de unos nuevos procedimientos, ya no normativos legales, sino de un nuevo tipo de normatividad, en este caso basada en la calidad. Esto enlaza con otro posible peligro que es no acertar con las expectativas que el cliente tiene de un servicio o de una prestación concreta.

Si la calidad descansa sobre la percepción, cuando esta sea incorrecta o mal interpretada por los altos responsables de la gestión pública pueden producirse una serie de «catástrofes» en cascada. El siguiente error sería establecer malas especificaciones o normas de calidad; a continuación, podemos encontrarnos con una posible divergencia entre las especificaciones de la calidad y la prestación efectiva del servicio; y, por último, dicha prestación, que puede cumplir las especificaciones previstas, cuando se comunique a los clientes quizá no reciba la adhesión prevista (Lloréns 2001: 206). Una mala percepción puede conducir a estos errores, pero cada uno de estos escalones genera discrepancias propias que pueden poner en peligro la calidad. De esta manera, la percepción, tomada como valor declarado, entraña importantes peligros para ser la única referencia, o la más importante, de la actuación pública.

La satisfacción del cliente, señala Beltrán (2000: 85), «parece descansar más en elementos propios del acto de prestación que en el objeto mismo de ella». Si esto presenta riesgos a la hora de determinar la calidad, se puede producir un enorme salto en el vacío entre lo que el ciudadano declara que le satisface, en la agregación de la satisfacción de los servicios realizados a un mismo ciudadano, la acumulación de la satisfacción de todos los ciudadanos, la decisión política y el resultado de las elecciones. Añádase a esto la dilución de responsabilidades que supone para el político adoptar decisiones bajo estas circunstancias. Si todo descansa en la percepción, como parece indicar la calidad, y en la opinión declarada por el ciudadano, se corre el riesgo de que el ciudadano actúe en contra de lo expresado, quizá no porque desee engañarnos, sino porque sus valores declarados no coinciden con los que utiliza para actuar. Esto es debido a que «no cuenten los hechos sino la valoración que los ciudadanos les dan, lo que significan para ellos» (González 2001: 43).

Además de los problemas anteriores, la calidad lleva en su interior el germen de su relatividad. Ya no se trata de satisfacer a clientes en general, ni a los concretos de un servicio público; la lógica de la calidad lleva a adaptarse a cada caso, a individualizar la oferta según el perfil del cliente. De esta manera, se puede afirmar que «no se puede ofrecer un producto estándar a clientes que solicitan un producto diferenciado y específico» (Castresana y Blanco 2000: 44). No que no está tan claro es cómo se conforma la voluntad general a partir de la satisfacción individual de los clientes. 
Lo propio de la actual sociedad de consumo es la subdivisión de la especialización de la oferta hasta llegar satisfacer el individuo concreto. Las nuevas tecnologías de la información y la comunicación ya la hacen posible en algunos sectores, y algunas Administraciones públicas se han aprestado a utilizar los teléfonos móviles o la introducción de los CRM (Customer Relationship Management) con el fin de obtener perfiles lo más precisos posibles de sus usuarios tratando de anticiparse a sus futuras necesidades.

A pesar de los riesgos que supone hacer descansar algunas decisiones públicas sobre la percepción ciudadana, lo cierto es que poco a poco se va extendiendo esta modalidad de adoptar decisiones. Las encuestas, las mediciones de la satisfacción, la elaboración de cartas de servicios, el establecimiento de indicadores que midan la satisfacción de los usuarios y consumidores públicos son moneda corriente.

No se critica su utilización, pero sí su exclusivo uso como método para lograr una Administración más eficaz y legítima. En el camino puede quedar la concepción integral de una Administración pública que cumple misiones de carácter político y social que transcienden a los meros actos concretos prestacionales. En ese enfoque domina una concepción de la acción pública como un juego adaptativo del tipo estímulo-respuesta, cuando las responsabilidades públicas son mucho más amplias que la prestación de bienes y servicios (Beltrán 2000: 51). Esa adaptación que propone la calidad no es en modo alguno nueva, ya que también se observa la existencia de una especie de servomecanismo del tipo decisión-evaluación en algunos enfoques del análisis de políticas públicas o en alguna de sus aplicaciones.

En fin, el enfoque de la calidad puede imponerse como una manera de hacer política que traslada la responsabilidad de la decisión al destinatario de los servicios, produciéndose una clara fragmentación de la realidad política y social.

\subsection{La nueva gestión pública o el triunfo sobre la política}

La existencia de una ideología comúnmente aceptada en materia económica en los países de nuestro entorno tiene su trasunto en el ámbito administrativo público. La nueva gestión pública (NGP) funciona como «una suerte de ideología, propiciando una única respuesta -contenida en la caja de herramientas de la nueva gerenciafrente a la diversidad de los problemas y las situaciones» (Olías de Lima 2001: 9).

El movimiento de la NGP comparte las ideas de eficacia y eficiencia y no le es ajena en modo alguno la calidad. Incorpora las soluciones adoptadas desde la perspectiva económica a la crisis financiera y presupuestaria del Estado de la reducción o reinvención del Estado, a las que añade la desregulación en consonancia con las medidas anteriores que proclaman, casi axiológicamente, la bondad del mercado y de la sociedad, y de paso se relega una visión que se considera demasiado legal y juridicista de los asuntos públicos, visión que es considerada por algunos la causante de las ineficacias de la Administración pública.

Para la NGP el mercado garantiza mejor el cumplimiento de los valores sociales y la Administración pública es inferior a la privada, por lo que esta debe ser minimizada. Se concluye que se precisa un nuevo tipo de gestión pública que adopte los principios éticos y la forma de actuar en los negocios (Baena 2000: 107). Obviamente, a esta conclusión no se podría haber llegado sin los transcendentales cambios experimentados desde la década de los setenta del siglo pasado y sin que, como señala Offe (1984), las contradicciones del capitalismo avanzado alcanzasen una gran dimensión que obligase a que la Administración se adaptase con el fin de dar una respuesta más eficiente a los constantes retos que se le plantean fruto de las contradicciones a las que se ve sometida. 
Al predominio del mercado se une una vuelta a la sociedad. Es más, para algunos, ambos términos son equivalentes. Ideas como la devolución de poderes a la sociedad o la amplia participación de los grupos sociales en los asuntos públicos no pueden separase de los principios en los que se sustenta la NGP, ya que ambos tienen como efecto, quizá no buscado en todos los casos, la reducción del Estado y, en muchas ocasiones, de lo público tal y como se venía concibiendo.

Lo público ahora es un espacio de interacciones sociales que se condicionan unas a otras con el fin de resolver los problemas de acción colectiva. Se teoriza sobre las redes de compromiso cívico cimentadas en la participación espontánea en grupos. El efecto de todo ello es la creación de lo que se denomina capital social como resultado de las «características de una sociedad al facilitar acciones coordinadas» (Brugué y Gallego 2001: 51). Estas acciones estaban antes articuladas principalmente por el Estado y su Administración pública, aunque no deja de haber autores que entienden que se trata de nuevas formas de ejercicio del poder que le permiten a ésta ser más omnipresente creando lo que se denomina un Estado «neonormativo» (Olías de Lima 2000: 32). En cualquier caso, la cuestión esencial no parece que sea lograr acciones coordinadas, sino dar respuesta a las necesidades sociales.

Las preocupaciones de la NGP se centran en el peso creciente otorgado al entorno y a los clientes; la búsqueda de una visión de conjunto; la selección rigurosa de objetivos y la especialización; la preocupación por el futuro o la prospectiva; la importancia de los costes y la consideración del personal como factor crítico (Olías de Lima 2000: 30). Algunas de ellas no son nuevas y otras parece que se han quedado en un mero deseo, al menos en su aplicación a la realidad administrativa española, como es el caso de la búsqueda de la visión de conjunto. Ésta se ve dificultada por la indagación de la satisfacción de los clientes de cada uno de los servicios públicos y el énfasis en los costes, que suelen referirse a unidades desglosadas de una organización común. Se puede afirmar que el énfasis en los resultados de la acción pública desvía la atención de los ciudadanos de las reformas propias de la etapa anterior, básicamente las estructurales y funcionariales (Beltrán 2000: 52).

Lo transcendente de estas preocupaciones es que en su aplicación concreta a través de las técnicas apropiadas pretenden un cambio cultural (Pollit 1995: 203) y, en buena parte, se puede decir que se ha logrado a la vista de las estrategias desarrolladas por las distintas Administraciones públicas de nuestro entorno y en concreto las españolas.

El cambio cultural producido en la gestión pública ha supuesto la ocultación de las funciones y del rol político de la Administración pública (Baena 2000: 117-8). Esto se ha logrado mediante la potenciación de la racionalidad económica y de sus instrumentos, de modo que la NGP actúa como una ideología en el plano de la acción pública simplificando su realidad (Olías de Lima 2000: 9). El éxito en la gestión se encomienda a los gerentes a los que se les otorgan plenos poderes para poder llevar a cabo su misión. Estos gerentes normalmente provienen del sector privado en el caso de las grandes corporaciones públicas o se encuentran profundamente culturizados en los valores privados si tienen un origen funcionarial. El resultado es la indiferenciación entre la política y la Administración y la dilución de las responsabilidades políticas, y por tanto ante los ciudadanos, de los gerentes de los servicios públicos.

Con todo, el cambio más transcedente es que la NGP parece que ha logrado lo imposible: «una adhesión que transciende la división entre partidos de derecha e izquierda». La coincidencia alcanza al predominio de los valores de mercado y de las organizaciones comerciales, a la vez que en el descrédito del Estado y de sus responsables y empleados (Olías de Lima 2000: 8). De esta manera, se pasa a señalar que «la Administración debe justificar en cada caso que su actuación directa es necesaria»; que «la privatización no tiene por qué rechazarse como opción moder- 
nizadora»; que «la utilización de entes instrumentales, por parte de la Administración, responde sobre todo a criterios de eficacia y flexibilidad y no de eficiencia» (Villoria 1996: 379-85); o que, como se señala en el Informe Gore, «que las unidades del sector público deben actuar transplantando a éste ciertos aspectos de la gestión de la empresa privada» y que las unidades del sector público han de situarse o posicionarse frente al mercado (o frente a su mercado) como lo hacen las empresas privadas y actuar en consecuencia» (Baena 2000: 112-14).

Se puede afirmar que la NGP ha tenido bastante éxito en su labor pedagógica de los altos responsables de la gestión pública y así, como antes se creía que el mero cumplimiento de la ley bastaba para lograr la legitimidad, hoy se cree que la aplicación generalizada de principios/técnicas como la descentralización, la subsidiariedad, la devolución de poderes, la creación de entes instrumentales, la introducción del coste/beneficio, la aplicación de los criterios de satisfacción del ciudadano-cliente o la evaluación de rendimientos de los empleados públicos devengarán naturalmente la misma legitimidad para la Administración pública que, al parecer, tenía antaño.

Estos efectos en la sociedad y en la cultura política no han pasado desapercibidos para la literatura científica. Así, Frederickson (en Román 2000: 231) niega la compatibilidad entre ética y algunas de las medidas de la NGP, afirmando que «los principios de la burocracia pública son, por definición, más éticos que los de las empresas y los individuos que actúan ateniéndose a las reglas del mercado». En este mismo sentido se pronuncia Keating (1997: 115-116) al preguntarse si los valores de la NGP no cuestionan la legalidad, el interés general, la experiencia y la profesionalidad de los funcionarios públicos en la adopción de decisiones políticas, o si la orientación al logro de unos objetivos es una base filosófica suficiente para la Administración pública.

Tras unos años de NGP cabe preguntarse si es posible conciliar la nueva cultura de modernización del Estado y de sus estructuras con el principio de legalidad. Ésta se vincula al viejo ejercicio de la autoridad y no al logro de la legitimidad democrática. La solución a la antítesis planteada se trata de resolver mediante la configuración y el mantenimiento de un espacio de codirección adecuado y el equilibrio entre las partes implicadas en cada política (Villoria 1996: 279-85). El precio a pagar por esa relegitimación de la legalidad es la proliferación de las leyes dictadas para satisfacer las políticas e intereses de los grupos en juego, que no hay que olvidar que no incluyen a la gran mayoría de los ciudadanos.

El modelo cultural de la NGP basado en la efectividad gubernamental no garantiza por sí mismo la democracia de alta calidad (Lipjhart 2000: 280), como ya hemos visto al tratar la diferencia entre la legitimidad de resultados y la institucional. Tampoco los valores propios del sector privado comercial evitan la aparición de algunos de los males clásicos como la corrupción, como tenemos ocasión de ver con cierta frecuencia.

Es posible que los mejor situados para hacer valer sus criterios, deseos y necesidades, o simplemente estén mejor informados, obtengan más beneficios del sistema que el resto (Alvira 2000: 74), como se pone de manifiesto en la evolución de los gastos sociales en la OCDE desde 1960 a 1990, que permite apreciar que la igualdad de oportunidades en materia de enseñanza o de acceso a los servicios sanitarios beneficia más a las clases medias que a los grupos necesitados (Beltrán 2000: 91). Lo que guarda relación con estudios más recientes que apuntan que «la general satisfacción con la mejora de los servicios públicos se reconoce más bien por los grupos que menos se benefician de las prestaciones sociales de la Seguridad Social» (De Miguel y De Miguel 2001: 55). La NGP tampoco parece mejor preparada que otras opciones para evitar estos rasgos de inequidad y es probable que sea más proclive a acentuarlos.

Se puede advertir el paso de la condición de ciudadano a la de cliente de las Administraciones públicas (Offe 1984: 35). Pero si lo anterior es cierto, también lo es que está apareciendo un nuevo escenario del que se deriva 
un ciudadano que se siente con derecho a orientar las actuaciones públicas y a exigir un nivel de preparación y disposición en los altos responsables públicos de gestión (González 2001: 61). Este sentirse con derecho procede de su dimensión de «ciudadano-contribuyente». Como un ciudadano que está aportando los recursos económicos para la actuación de esa Administración pública. Además, el ciudadano también aporta su participación en la vida política y en la construcción y mantenimiento de la sociedad, de la que se siente partícipe y corresponsable.

\subsection{Legitimidad y gobernabilidad}

La preocupación de la Administración pública por los intereses sociales está presente desde el comienzo de su teorización. Así, Florentino González en 1840 definirá la Administración pública «como la acción de las autoridades sobre los intereses y negocios sociales, que tengan el carácter de públicos, ejercida conforme a las reglas que se hayan establecido en una nación para manejarlos» (1994: 75).

En la actualidad la atención no está ya puesta en los aspectos legales-normativos ni en el ejercicio en exclusiva por el poder público de la autoridad sobre la sociedad, ya que hemos visto que su sola referencia no basta para lograr la credibilidad del gobierno y de la Administración pública, sino en la aptitud de un sistema para regular los conflictos sociales, lo que remite al rendimiento del sistema político. Pero esta aptitud no es espontánea, sino que responde a la configuración institucional y a la capacidad de los gobiernos de manejar dicha configuración con el fin de lograr una mayor legitimidad. A la efectiva capacidad de respuesta a las demandas de los ciudadanos individuales y de sus grupos es a lo que denominamos gobernabilidad.

El enfoque de la gobernabilidad parte de un poder compartido de las instituciones concebidas formalmente con los grupos integrantes de la sociedad, que además de tenerlo lo ejercen sobre ésta para tomar decisiones sobre la vida pública y el desarrollo económico y social. Se puede decir que la preocupación por la gobernabilidad ha desplazado a las políticas públicas (Baena 2000: 250), aunque de éstas perviven con fuerza los aspectos decisionales de regulación social y de evaluación de la actuación pública, perdiendo intensidad su concepción como forma explicativa integrada de la acción pública y administrativa.

La gobernabilidad se cimenta en una serie de valores que no son todos originales, sino que provienen de otras concepciones: pluralismo, participación, representatividad plena, decisiones políticas reflexivas y participadas, solidaridad, equidad, ética, responsabilidad y eficacia. No presenta una teorización específica de cómo lograr una mejor legitimidad de resultados, por lo que puede decirse que puede asumir las técnicas instrumentales de la NGP situándolas en un contexto de valores más sociales. Pero la NGP no es sustituida por la gobernabilidad, sino que sus rasgos más relevantes son aprovechados por ésta, en este caso la preocupación por actuar de una manera lo más parecida posible al sector privado comercial, aunque ahora se exige una eticidad distinta.

Alguno podría ver en el énfasis en la gobernabilidad y su complejo sistema de intereses y grupos sociales una desestatalización y, por tanto, una continuación de las tendencias reduccionistas de lo público emprendidas desde los años setenta del siglo pasado. El que la gobernabilidad no aporte un cuerpo teórico en la forma de actuación de la Administración pública frente a los postulados de la NGP puede abonar esta idea.

Junto a la gobernabilidad ha aparecido -se ha comentado ya anteriormente- la preocupación por la ética o por la incorporación de unos nuevos valores a la actuación pública que sean congruentes con la gobernabilidad. Se puede hablar de un rearme ético frente a las posiciones extremas mercantilistas propias de la NGP, de unos 
valores que permitan lograr la cohesión social que ahora se percibe como mucho más compleja desde el enfoque de la gobernabilidad. Ese rearme trata de moderar las tendencias reduccionistas de la iniciativa pública y administrativa manteniendo la legitimidad del Estado y de su Administración pública.

A los efectos de nuestro estudio interesa retener que la gobernabilidad suaviza las aristas más agudas de la NGP pero mantiene casi intactos sus valores por lo que a la Administración pública se refiere. Es cierto que la gobernabilidad enfatiza en la autocoordinación social para el logro de los objetivos de la sociedad, pero esto no es completamente original y ya estaba previsto, aunque con menor intensidad, en los postulados de la NGP. Lo que cuenta es que en ambos casos se trata de reducir el ámbito decisional público y de utilizar técnicas de eficiencia provenientes del sector privado comercial.

La gobernabilidad aporta la gestión en red con los grupos sociales y los individuos, pero esto afecta sobre todo a los procesos decisionales y de resolución de conflictos. También incorpora la gestión de determinados asuntos que podrían ser considerados públicos anteriormente, o que ya eran gestionados en ese ámbito, por determinados grupos sociales. Esto sería una especie de outsourcing social. El núcleo prestacional del Estado, no obstante, se seguirá rigiendo por los ahora matizados principios de la NGP.

La gobernabilidad ha «civilizado» el énfasis en los resultados consolidando viejas tendencias neocorporativas a las que ahora se añaden las más novedosas sobre participación. La gobernabilidad, por tanto, no ha obligado a reconsiderar sustancialmente a los altos responsables de la gestión pública su posición sobre cómo emplear los medios públicos, por lo que coexiste sin grandes problemas con la NGP. Consecuentemente, las soluciones de gestión que se aplican a los problemas de la obtención de rendimientos suelen ser las mismas que las anteriores a la aproximación de la gobernabilidad.

\section{El marco operativo. El logro de la eficacia}

Hasta ahora se ha tratado el marco teórico en el que se suelen desenvolver las estrategias desarrolladas por el bloque Gobierno-Administración pública para incrementar la legitimidad a través de los rendimientos del sistema político. En este apartado se va a profundizar en cómo se han logrado perfilar esas estrategias. Como se ha comentado en diversos epígrafes anteriores, esto se realiza preferentemente a través de la obtención del valor declarado por los ciudadanos sobre cómo reformar o modernizar la Administración pública; lo cual es bien distinto a conocer los referentes de actuación operativos de dichos ciudadanos con el fin de obtener unos servicios públicos alineados con sus expectativas y necesidades. El valor declarado se ha logrado mediante las técnicas de encuestas cuantitativas y estudios cualitativos de grupos estratificados.

\subsection{Las preguntas sobre la eficacia de los servicios públicos}

Las propuestas de la NGP y del movimiento de la calidad que se han comentado en epígrafes anteriores tratan de lograr una mayor eficacia de los servicios públicos. Más concretamente, la NGP busca la especialización de los servicios públicos; su desburocratización; la clientelización, que trata de «promocionar» al ciudadano a actor de los servicios públicos y no sólo a receptor, incrementar la democratización y fomentar las iniciativas de mejora del servicio y de satisfacción del ciudadano; la evaluación de los servicios mediante la medición y ponderación entre éstos y los objetivos perseguidos; el aseguramiento de la reproducción del sistema tratando de que 
los procesos no se desvíen de los estándares establecidos; en fin, cambiar la cultura organizacional que es la principal causante de las resistencias al cambio (Olías de Lima, 2000: 12-20). Estas resistencias se concretan en el miedo a lo desconocido; falta de información; desinformación; factores históricos; amenazas al status; amenazas al poder; beneficios no percibidos; clima de baja confianza organizativa; relaciones pobres; miedo al fracaso; resistencia a experimentar y poca flexibilidad organizativa (Ramió 1999: 210).

Los estudios cuantitativos y cualitativos que se realizan sobre el funcionamiento de la Administración pública y sobre sus resultados asumirán las premisas de la calidad y de la NGP en sus cuestionarios y metodología. Además, los ítems preguntados al ciudadano sobre el funcionamiento y la calidad de los servicios públicos son congruentes con las recomendaciones realizadas por determinados informes específicos dirigidos a optimizar las organizaciones públicas. Así, el Informe Nolan señala los siete principios de la vida pública: ausencia de interés personal, integridad; objetividad; responsabilidad; transparencia; honestidad, y ejemplaridad (1995: 14). Por su parte, el Instituto de Estudios Fiscales señala que los valores que habría que potenciar al máximo en las organizaciones públicas son la lealtad institucional; la integridad, objetividad e independencia; la competencia técnicoprofesional; la confidencialidad, y el respeto a las personas. La mala noticia es que seguir estos y otros principios similares no garantiza por sí mismo el logro del éxito (Ramió 1999: 203 y ss), como se pone de manifiesto reiteradamente en la opinión de los españoles expresada en las encuestas y estudios cualitativos.

Entre 1979 y 1995 el CIS pregunta en tres ocasiones a los españoles sobre la opinión que les merece la administración que del dinero proveniente de los impuestos realiza el gobierno de turno. Las opciones varían según las encuestas, pero oscilan de la opinión «ha administrado muy bien» a la de «ha tirado por la ventana» (CIS 1979. Estudio 1.191; CIS, 1990. Estudio 1.901; Barómetro del CIS de noviembre de 1995). Aunque los ítems no son homogéneos, cabe resumir que los españoles que piensan que el Gobierno ha sido eficaz o muy eficaz en el gasto de sus impuestos oscilan, en los tres cortes -1979, 1990 y 1995- del 12 al 13 por cien. A la posibilidad, en 1979 y 1990, de que «ha desperdiciado algún dinero», se apuntan el 41 y el 37 por cien de los encuestados, respectivamente. En 1995 creían que el Gobierno administraba regularmente sus impuestos el 33\%. Los que tenían la peor opinión de la eficacia del Gobierno en 1979 y 1990 alcanzaban el 23 y el 34 por cien, respectivamente, y en 1995 los que pensaban que la administración había sido mala o muy mala alcanzaban el 46 por cien.

Hay que señalar que en 1990 comenzaban a aparecer en la opinión pública importantes casos de corrupción vinculados a miembros del Gobierno y que en noviembre de 1995 la corrupción política era el segundo problema declarado por los ciudadanos españoles (Barómetro del CIS de noviembre de 1995). Relacionado con esto, se encuentra la opinión de los ciudadanos de que los gastos con motivo de los eventos de 1992 (AVE, Expo, Olimpiadas) denotaban un «comportamiento ostentoso y derrochador» (CIS 1994: 7). En resumen, la opinión de los españoles sobre el rendimiento y la eficacia de sus Gobiernos se puede calificar de mala.

Al lado de estas opiniones, hay que situar el que algunos apunten la «elasticidad sin límites, la insaciabilidad, de la demanda de calidad» por parte de los ciudadanos a sus Administraciones públicas (Beltrán 2000: 86); que este tipo de contestaciones de los ciudadanos responde a la disociación entre las demandas y los costes asociados a ellas (ESDEM 2000); o que en 1997 «son muchos más los que señalan que han aumentado los impuestos (61 por cien) que los que señalan la mejora de los servicios públicos (43\%)» y que esta denominada asimetría fiscal esconde realmente un juicio político (De Miguel y De Miguel, 2001: 64 y 66), que afecta no sólo al grado de satisfacción política, sino probablemente a la propia legitimidad del sistema. Esto lleva a preguntarse sobre qué hacer y cómo profundizar en lo que los ciudadanos desean, con el fin de lograr que el Gobierno obtenga una mejor eficacia de su actuación, para que logre una mayor legitimidad. 
Los estudios tratan de buscar las preguntas adecuadas que permitan orientar la acción de gobierno, pero los obstáculos para lograrlo son importantes, y no se refieren sólo a los problemas metodológicos de la NGP o de la calidad, que son muchos, o de la sociología o la ciencia política actuales, sino a la existencia de una serie de disociaciones importantes entre el ciudadano y su realidad. La primera es que el individuo no siente una predisposición especial por vivir en la «realidad real» (Murillo, en Beltrán 2000, 162-3) y puede hacer figuraciones, representaciones o construcciones de aquella, por lo que al ser preguntado sobre aspectos de la realidad puede pronunciarse de forma diferente a como realmente actúa. Es lo que hemos venido denominando diferenciación entre el valor declarado y el valor operativo.

Otra dificultad derivada de la anterior proviene de que los ciudadanos tienen una percepción fragmentada de la realidad, relacionándose con su entorno como si de planos netamente diferenciados se tratara, haciendo posible posiciones diversas en cada uno de ellos. Esta fragmentación afecta también a la forma que tienen de ver a la Administración pública, a la que perciben, lógicamente, como plural, pero no sólo por lo que a los niveles territoriales se refiere, sino por servicios, teniendo, en ocasiones, dificultades para atribuir las acciones de un servicio a la Administración que las presta efectivamente. Este tipo de diversificación se completa con que la forma en que el ciudadano se acerca a la Administración es diferente según sea lo que demande de ella.

La dificultad anterior se vincula a otra que consiste en que es posible que el ciudadano tenga problemas para evaluar su relación con la Administración pública en función de los objetivos políticos de su Gobierno. Puede ser que el ciudadano no conecte las actuaciones administrativas con los objetivos declarados por el Gobierno correspondiente. De ser esto cierto podría existir una dificultad de tipo casi estructural para trasladar el rendimiento a la legitimidad de tipo institucional o, al menos, a la satisfacción política.

Por último, los ciudadanos no siempre son capaces de percibir correctamente los éxitos o fracasos de la Administración pública con la que tratan, simplemente porque no se relacionan directamente con ella. Así, en 1989 el 8 por cien de los encuestados declaraba que se dirigían siempre a una gestoría cuando solicitaban un servicio público y un 28 por cien lo hacía algunas veces (CIS 1989. Estudio 1.848).

Por lo que respecta a la cumplimentación de la declaración del IRPF, el 34 por cien de los ciudadanos declaraba en 2002 que se la realizaba un asesor o un gestor, y el 14 por cien, una entidad bancaria, y sólo el 15 por cien declaraba que lo hacía personalmente frente al 22 por cien que lo hacía en 1995 (CIS 1995. Estudio 2.187; CIS 1996. Estudio 2.219; CIS 1997. Estudio 2.253; CIS 2002. Estudio 2.462; Alvira 2000. Estudio 171).

Lo anterior significa que «no todos los contactos o relaciones reales son percibidos como tales por el administrado», y ello debido a la razón anterior y al hecho de que la relación con la Administración la asocian a «contactos de carácter burocrático que, por tanto, serán los que concentren su atención y en relación a los cuales elaborará sus imágenes, actitudes y valoraciones» (Esdem 2000).

Si consideramos los ítems incluidos en las encuestas sobre valoración de la Administración, satisfacción de los servicios públicos, sobre los valores o preferencias del ciudadano respecto de sus Administraciones públicas o sobre la satisfacción ciudadana o la calidad del funcionamiento de los servicios públicos, veremos que sitúan al ciudadano en un plano claro de cliente alejado de las decisiones centrales de las políticas públicas. Además, observaremos a un ciudadano al que no se le pregunta sobré cómo quiere que se comporten sus altos responsables de la gestión pública.

El resultado de los diversos estudios realizados arroja unas imágenes de los ciudadanos sobre la Administración pública que se concretan en: 
- ineficacia y falta de agilidad;

- aumento de la complejidad burocrática y creciente normativización de los espacios sociales e individuales;

- resistencia de los funcionarios al cambio y a la modernización que supondría la introducción de la competencia. (Esdem 2000)

Desde el punto de vista de las acciones que deben desarrollarse para mejorar los resultados de la Administración pública, las respuestas sobre el funcionamiento de los servicios públicos se pueden resumir en lo que González (2001: 37-8) denomina «efectos no deseados» por los ciudadanos en su relación con la Administración pública:

- Burocracia, duplicación de trámites. Excesivo papeleo.

- Lentitud de los procedimientos.

- Falta de información y de claridad en las respuestas.

- Distancia «altiva», a veces, del funcionario. Poca amabilidad.

A combatir estos efectos, que deben considerarse de primer nivel o de ineficacia, se van a dedicar esencialmente las estrategias de los altos responsables de la gestión pública de las Administraciones públicas españolas al menos de los últimos veinte años, con el fin de lograr mejores rendimientos del sistema político.

\subsection{La forma de lograr la eficacia: gerentes vs. ciudadanos}

\section{La exigencia de la responsabilidad y su conexión con la legitimidad}

La NGP postula como uno de sus principios fundamentales «dejar que los gerentes gestionen». Esta cuestión presupone una fácil delineación entre las tareas que realizan los gestores y las que realizan los políticos. También puede conllevar una concepción de una Administración pública que sólo o principalmente gestiona. Ya se han comentado en otro apartado los efectos que este planteamiento tiene en la concepción de la política; ahora se va a abordar el asunto de la responsabilidad.

La legitimidad del sistema democrático descansa en la transparencia del itinerario que va desde el voto depositado por el ciudadano en la urna hasta la acción pública que se ejerce sobre el ciudadano. Ésta es legítima porque es posible realizar en cada paso del itinerario la vinculación entre el voto y la fase específica de la acción pública y, especialmente, porque es posible exigir la responsabilidad política de cada actuación a la institución y a los representantes concretos de ésta. Existe un itinerario ascendente de legitimidad y otro descendente de responsabilidad que se alimenta el uno del otro. Si se quiebra el circuito, el ciudadano puede llegar a percibir una actuación ilegítima en mayor o menor medida, lo que puede producir insatisfacción política, desafección o pérdida de legitimidad del sistema democrático, y puede generar diversos comportamientos, pudiendo ser el más visible el de la abstención (CIS 1996. Estudio 2.212).

Los funcionarios y empleados públicos de la Administración son responsables de algunos de los escalones del itinerario descrito, pero no son los destinatarios del voto ciudadano. Esto no deja de tener interesantes consecuencias para la Ciencia Política y la Ciencia de la Administración. Para el ciudadano, el responsable último de la actuación pública, en cualquier dimensión, no puede ser otro que el político. En los sistemas representativos como el español, el político se identifica predominantemente con los máximos responsables políticos de cada 
Gobierno, dado el predominio casi absoluto que los ejecutivos tienen en la vida política. La legitimidad del gerente, funcionario o empleado público descansa esencialmente en su sometimiento a la dirección política. Este es el corte más significativo entre política y Administración pública y no se difumina simplemente porque en muchas ocasiones sea difícil separar el papel de cada uno de los actores, políticos y funcionarios, en las diversas fases de las políticas públicas o en las funciones administrativas.

El resto de la legitimidad de los funcionarios y asimilados se basa en los procedimientos con los que fueron reclutados para entrar en la Administración pública, promocionados en su carrera administrativa y nombrados para un puesto concreto. Tienen tanta relevancia estos aspectos que suelen estar regulados con rango normativo superior y, en el caso de España, en la Constitución Española, donde se señala en su artículo 103.2 que el acceso a la función pública se regirá por los principios de «igualdad, mérito y capacidad», al que hay que añadir el de publicidad. Estos principios son los mismos que rigen para la promoción profesional y para la ocupación de la gran mayoría de los puestos de trabajo, exceptuándose los tres primeros principios para los nombramientos superiores de la Administración pública, y algunos otros menores, por motivos de confianza política o personal.

Nuestra cultura política, además, hace que la mayoría de los nombramientos políticos recaiga en funcionarios públicos, lo que además se ha convertido en una exigencia legal para los puestos de Director General y equivalentes y de Subsecretario de la Administración General del Estado.

La realidad anterior nos debe hacer reflexionar sobre la dificultad de trasponer sin más los principios generales adoptados bajo la óptica de la empresa privada o de otros sistemas culturales a nuestro sistema políticoadministrativo. Por otra parte, la doble legitimidad de los funcionarios determina que el ciudadano atribuya en determinados casos mayor legitimidad a las actuaciones de los funcionarios que a la de los políticos, debido precisamente a su naturaleza profesional. Eso es coherente con la valoración que los ciudadanos otorgan a la veracidad de unos y otros. Así, en 1995 para el 42 por cien de los ciudadanos los funcionarios generalmente dicen la verdad, mientras que esto sólo ocurre para el 18 por cien en el caso de los diputados y senadores y para un 14 por cien en el caso de los ministros del Gobierno (CIS 1995. Datos de Opinión 2). Las diferencias es posible que sean mayores si, por ejemplo, de lo que se trata es de que un político no haya recabado un informe preceptivo funcionarial o que lo haya desoído con graves consecuencias administrativas o políticas.

La NGP, con el fin de fortalecer el papel de los gerentes, distingue entre responsabilidad e imputabilidad. La primera operaría en el plano político, y sus consecuencias, en especial la dimisión, sólo serían exigibles «cuando se pueda demostrar la implicación personal del ministro en la mala gestión». La imputabilidad corresponde al plano de los gestores, quienes darían cuenta al Parlamento «de la marcha de los servicios». Los gerentes serían así los responsables directos ante el legislativo (Olías de Lima 2000: 24). Lo que sucede es que esta original distinción choca frontalmente con el circuito de legitimidad descrito entre el ciudadano y los servicios que se le pres$\tan$ y con la realidad política en la que los gerentes no se presentan a las elecciones ni tienen un papel relevante ante la opinión pública. El efecto final de la separación entre responsabilidad e imputabilidad probablemente no sea sino la impunidad de determinados políticos, algo que, está en el centro de la pérdida de legitimidad del sistema político en las democracias representativas.

\section{Las estrategias de los políticos y gerentes y las reclamadas por los ciudadanos}

Las medidas que los gerentes de los servicios públicos creen que hay que realizar para superar los «efectos no deseados» del funcionamiento de la Administración pública no tienen por qué coincidir con las que propon- 
gan los ciudadanos. Ya se ha comentado anteriormente que pueden surgir importantes discrepancias entre los clientes y los gestores, ya que a ambos se les otorga la facultad de plantear iniciativas y hacer valer sus puntos de vista; lo que sucede es que el árbitro del interés público no es el político, ni el gestor, sino el ciudadano. En pura lógica de la calidad, no cabría sino dar la razón a la opinión declarada por los ciudadanos sobre qué debe hacerse para mejorar los servicios. Sin embargo, esto suele estar lejos de suceder, salvo en cuestiones que tienen que ver normalmente con los aspectos meramente prestacionales y en aspectos relacionados, como hemos visto, con la eficacia.

Las recetas de la NGP para superar los «efectos no deseados» son: reducción de tamaño del sector público; descentralizar las organizaciones (volver a integrar al Estado en su medio societario); construir organizaciones con jerarquías aplanadas (se reduce tiempo, se reducen ruidos, información reticular); ruptura del monolitismo y especialización (agencia unida a la organización principal por un contrato, control por auditoría de gestión o contable); desburocratización e introducción de la competencia; desmantelamiento de la estructura estatutaria (de estabilidad en el empleo y en el puesto y del actual sistema retributivo); además de lo ya señalado sobre la clientelización y el cambio de cultura (Olías de Lima 2000: 12-20). La mayoría de propuestas son de carácter estructural y exigen un largo proceso y, como se ha señalado, aunque se lograsen realizar no es seguro que con ello se obtuviera el éxito que se persigue. Por otra parte, no es fácil que el ciudadano pueda comprender una relación directa entre el establecimiento de jerarquías planas o la creación de agencias con una mejor respuesta a sus demandas, aunque, en general, cada una de ellas es objetivamente necesaria.

Las recetas anteriores coinciden con otras propuestas para el caso español que parten de una serie de principios comunes a la NGP y al movimiento de la calidad, aunque también se basan en los referidos principios de la vida pública del Informe de Nolan. Se incorporarían a ellos, aunque no con total originalidad, el énfasis en la responsabilidad pública para lograr la mejora de las condiciones de vida de los ciudadanos, la austeridad y la no autosuficiencia de la Administración pública. Los ejes de acción para poner en marcha los procesos modernizadores coincidirían básicamente con las propuestas de la calidad y la NGP (Gomá y Subirats 1998: 403-404), por lo que plantearían los mismos problemas que los comentados en el párrafo anterior.

Por su parte, las propuestas de los ciudadanos para superar los «efectos no deseados» tratan de atacar sus causas inmediatas, aunque también remiten a raíces más profundas como iremos viendo en lo que sigue a continuación, que son las conclusiones de la investigación realizada por González (2001: 40 y ss), a las que se van a añadir una serie de comentarios con el fin de integrarla en el objeto de nuestra propia investigación.

Ante los «efectos no deseados», los ciudadanos manifiestan una serie de objetivos de mejora de las necesidades experimentadas en la actualidad y que no son satisfechas por la Administración pública. Los principales objetivos de mejora son:

- Simplicidad y rapidez en los trámites con la Administración.

- Amabilidad de los funcionarios

- Motivación y preparación de los funcionarios

- Información válida y accesible al ciudadano (no tener que volver).

Estos puntos serán los referentes de verificación que los ciudadanos establecen para que la Administración pública aborde los procesos de modernización o reforma. Es lo que entienden que tiene que hacer ésta para que le quiten el «dolon» no deseado de esa relación, esas pérdidas de tiempo y esfuerzo. Por dolor, en este contexto, se denomina al saldo negativo resultante entre las expectativas de los ciudadanos sobre el funcionamiento de los 
servicios públicos y sus resultados reales. En esta situación el ciudadano se siente con derecho a que le presten los servicios con eficacia, de ahí que no otorgue prácticamente valor a que se produzca ese resultado.

Si repasamos los objetivos de mejora señalados, veremos que lo son también de todos los planes de modernización o de calidad de las Administraciones públicas españolas. Es a su consecución a lo que se dedica la mayor parte de la energía política y administrativa con el fin de obtener mejores rendimientos de las instituciones y especialmente de la Administración. El resto de los esfuerzos se reparten, sólo en algunas instituciones, en la participación y la descentralización. Esto explicaría, siguiendo la investigación de González, el poco éxito obtenido por los diversos gobiernos con sus diversos planes para lograr una mayor legitimidad institucional. También explicaría la sensación generalizada entre nuestros políticos de que «la Administración no tiene arreglo».

En la investigación que se comenta, aparecieron entre los anteriores objetivos o referentes de verificación otra serie de ellos que no eran congruentes con la resolución de los principales «efectos no deseados» reflejados por esos mismos ciudadanos en la investigación de la situación actual. Así, apareció en segundo lugar de importancia la mejora de las infraestructuras, además de: justicia rápida y sencilla; mejoras de educación, mejoras en sanidad; prestaciones sociales; ausencia de paro; calidad de vida ciudadana. Estos efectos ya no hacen referencia directamente a la ineficacia, sino a otra dimensión distinta de aquella a la que sitúan habitualmente a la Administración pública al hablar de modernización.

Con objeto de saber si estos objetivos sólo son meras manifestaciones de los ciudadanos, un valor declarado, o, por el contrario, formaban parte de su valor operativo, se les preguntó a los ciudadanos sobre aquello que en la actualidad está impidiendo el logro de los resultados máximos que esperan de la Administración pública. Si distinguimos entre el escenario actual y aquel que se apuntaba como una nueva dimensión, encontramos que en el escenario actual los impedimentos son:

- Falta de mentalidad empresarial en la Administración pública. Burocracia.

- Falta de conciencia de «servicio» al ciudadano.

- Falta de evaluación y exigencia a los funcionarios. No tienen motivación.

- Lentitud de la modernización. Objetivos políticos poco ambiciosos.

- Demasiada prioridad en lo político. Visión a corto plazo.

- Por su parte, en la nueva dimensión apuntada o escenario emergente aparecen los impedimentos de:

- Falta de preparación de los gestores públicos.

- Mala gestión de fondos públicos. Se invierte en actuaciones sin «efectividad social».

Estos impedimentos, en especial los primeros, no se diferencian del diagnóstico realizado por la NGP, aunque el escenario emergente nos remite a unas estrategias que exceden con mucho de lo que en la actualidad se está realizando para lograr un mejor rendimiento de las Administraciones públicas a través de sus diversos planes de modernización y calidad.

En el caso español, las actuaciones destinadas a remover los impedimentos del denominado escenario emergente o bien no han tenido el suficiente éxito para que los ciudadanos sigan declarando esos impedimentos, o bien no se ha actuado debidamente sobre ellos (CIS 1992. Estudio 2.019). En este sentido, la investigación que se comenta confirma la necesidad de actuar sobre lo que en la actualidad está impidiendo el logro de los resultados máximos establecidos por los ciudadanos como referentes de la actuación de la Administración pública, tanto en uno como en otro escenario. 
Las estrategias propuestas por los ciudadanos para el logro de los resultados deseados por ellos serían en el escenario actual:

- Proyecto de modernización empresarial de la Administración. Evaluación funcionarial y responsabilidades. Si no se cumple, despidos.

- Que el ciudadano sea considerado el «centro» de la gestión pública.

- Prioridad política para la modernización de la Administración pública.

Por su parte, las estrategias propias del escenario emergente son:

- Controlar las actuaciones de los responsables públicos y exigir responsabilidades.

- Gestores públicos expertos en su área de actuación.

Las estrategias de los gerentes públicos para la reforma o modernización administrativa comentadas con anterioridad, que coinciden básicamente con las de los políticos que los nombran, concuerdan sustancialmente con las propias del escenario actual, aunque su reiteración por los ciudadanos manifiesta que todavía no se han alcanzado los objetivos que se pretendían conseguir con ellas o que no se han implantado lo suficiente. Es de destacar la segunda, por la que el ciudadano desea sentirse «centro» de la gestión pública, advirtiendo que, en el contexto de la investigación que se comenta, no es posible equiparar ciudadano con cliente. El asunto de la prioridad política se refiere a la voluntad efectiva de los dirigentes políticos de ir más allá de las meras declaraciones o buenas intenciones.

Donde se encuentra un valor diferencial ciudadano respecto a las estrategias de los gerentes de la NGP es en las estrategias que se incluyen en el escenario emergente. Los ciudadanos exigen responsabilidades de sus actuaciones a los políticos y altos funcionarios de la gestión pública porque constatan que ellos mayoritariamente no las asumen. Es cierto que, como hemos visto, para la NGP la responsabilidad es uno de los ejes de acción para poner en marcha los procesos modernizadores, pero se refiere específicamente a la de los funcionarios o gerentes. También hemos tratado con cierto detalle el problema del circuito de la legitimidad entre el ciudadano y su voto y la acción pública que invalida la distinción entre la responsabilidad y la imputabilidad y que conduce a la irresponsabilidad del político. Por tanto, para el ciudadano la responsabilidad alcanza en primer término al político y de ahí hacia abajo, de tal manera que esa cadena de mando permita hacer responsable al superior por las acciones cometidas por los que actúan bajo su responsabilidad.

La segunda estrategia del escenario emergente, nombrar gestores públicos expertos en su área de actuación, puede parecer una cuestión menor. Se piensa que ya se cumple, puesto que, como hemos comentado, la gran mayoría de los altos responsables de gestión pública son profesionales de la Administración pública, y porque el nombramiento de gerentes para el sector público provenientes del sector privado suele recaer en personas de las mismas áreas de actividad. Sin embargo, no es infrecuente observar que se considera un valor en la carrera política el haber pasado en el gobierno por áreas de actividad bien diferentes, ya que se considera que el saber necesario para ocupar los más altos puestos de responsabilidad pública es de naturaleza estrictamente «política».

El ciudadano exige que todos los altos responsables, comenzando por los superiores, sean expertos en su área de gestión, como es lo habitual en el sector privado comercial y no comercial (CIS 1988. Estudio 1.741; CIS 1990. Estudio 1.878; CIS 1992. Estudio 2.019). Que esto no suceda responde a una manera de hacer política que el ciudadano parece rechazar. Las estrategias para evitar estos comportamientos no pueden figurar en los planes de modernización porque éstos no incluyen al estrato político superior de la Administración pública, ni normalmente al resto de los altos responsables de la gestión pública. 
En resumen, las estrategias que desarrollarán los gobiernos para lograr un mejor rendimiento de sus instituciones y, en especial, de sus Administraciones públicas se centrarán en evitar los efectos no deseados por los ciudadanos en su relación obligada con ellas, lo que es propio de lo que se ha denominado escenario actual, sin llegarse a plantearse la necesidad de intervenir en el escenario emergente. Éste está dominado por valores de tipo emocional y no sólo materiales, como sucede en el actual. En el emergente, el ciudadano no acepta el rol de administrado, sino que adopta el de ciudadano-contribuyente y exige un estilo de relación a sus responsables públicos distinto. La relación entre ambos escenarios funciona de la manera en que el escenario actual, o nivel 1 de modernización, es condición necesaria para otorgar la legitimidad institucional, pero no es suficiente ya que esto corresponde al nivel 2 o escenario emergente. En la actualidad, aunque la mayor parte de los esfuerzos destinados a mejorar la legitimidad institucional se dirige a ese nivel 1, lo cierto es que los resultados alcanzados no son excesivamente buenos, y además son desiguales (CIS 1993: 2.054).

\subsection{La creencia en la mejor gestión de la empresa privada}

\section{La constatación de la creencia declarada}

Los ciudadanos tienen la oportunidad de contrastar todos los días los valores y los resultados de la gestión privada y de la pública y asignan con nitidez los valores de eficacia, responsabilidad, calidad, competitividad, iniciativa, motivación y buena organización al sector privado (CIS 1992. Estudio 2.019). Además, consideran que una de las causas que imposibilitan a los ciudadanos el logro de los resultados máximos que esperan de la Administración pública es su «falta de mentalidad empresarial». El resultado es que el ciudadano cree que la gestión de la empresa privada es mejor que la de la Administración pública.

Esta creencia se ve corroborada en varias encuestas del CIS. En 1992 el 49,9 por cien de los ciudadanos encuestados afirmaba que los servicios funcionaban mejor en el sector privado frente al 16,1 que creía que lo hacían mejor en el público. El resto hacía depender su preferencia del servicio concreto (CIS 1992. Estudio 2.019).

También en 1992 se le hacía a los ciudadanos esta pregunta: «En general y con independencia de su financiación pública, si los siguientes servicios fueran gestionados directamente por empresas privadas, ¿piensa usted que funcionarían mejor, igual o peor que ahora?» (CIS 1992. Estudio 2.019). En su respuesta el ciudadano se inclina por la prestación de los servicios esenciales por el sector privado en la sanidad, aunque en el caso de la enseñanza y los servicios sociales esta inclinación era menos acusada. Esto probablemente sea debido a que el ciudadano puede contrastar personalmente o por referencias directas el funcionamiento de esos servicios en el ámbito público y en el privado, ya que en el área de la enseñanza y en de los servicios sociales existe una amplia oferta privada. Hay que destacar que al preguntársele al ciudadano sobre esta cuestión se le situaba en un contexto de una financiación pública de los servicios con independencia de quién los prestase.

Este aspecto, el de la gratuidad, es determinante en todas las encuestas de este tipo, ya que el ciudadano puede confundir en muchas ocasiones lo público con lo gratuito. La gratuidad está garantizada en muchos servicios sociales prestados por instituciones no públicas y en la casi totalidad de la enseñanza privada obligatoria mediante el mecanismo de los conciertos de plazas y centros escolares, respectivamente. De ahí que sea delicado extrapolar del efectivo uso de los servicios la preferencia por la gestión pública o la privada, ya que situados en este dilema y no teniendo los recursos económicos suficientes, es lógico que la gran mayoría de la población se decante por lo público, como se observa en otras encuestas (CIS 1995: 2.186; CIS 1999: 2.318). Si a la población se la sitúa en otro contexto, como el de una enfermedad grave, el ciudadano se decanta por utilizar en mayor medida los hospitales privados. Así, en 2000 elegían esta opción el 16,5 por cien de los encuestados (CIS 2000. Estudo 2.394). 
En resumen, las preguntas del tipo quién debe «gestionar» o «pagar» un servicio pueden llevar a la confusión al ciudadano entre la gestión y la gratuidad del servicio (CIS 1996. Estudio 2.224; CIS 2000. Estudio 2.394).

La declaración, por ejemplo, de que la sanidad privada está mejor gestionada que la pública contrasta con las encuestas sobre satisfacción de los servicios hospitalarios y de atención primaria, en las que los ciudadanos muestran en 2000 sentirse muy o bastante satisfechos en más de un 50 por cien. A la vez expresan percibir una gran mejora en su calidad en los últimos diez años, más del 60 por cien, y una gran confianza, también más del 60 por cien, en que dentro de diez años funcionarán mejor. Sin embargo, los ciudadanos en 1995 declaraban una mayor confianza en la sanidad privada en aspectos tan importantes como en la calidad que ofrece o en que sus profesionales están mejor preparados (CIS 2000. Estudio 2.394). En el caso de Andalucía, en 1999 los aspectos mejor valorados de la sanidad privada eran la atención personalizada y la comodidad de los centros; y en la pública, la confianza en los profesionales, el número de centros y la tecnología sanitaria (Fernández y otros, 2001: 48 y 106).

Es posible que cuando en 1996 se manifiestaba preferencia por la sanidad privada, los ciudadanos se dejasen arrastrar por la creencia del mejor funcionamiento de lo privado o por el prestigio de determinados hospitales o clínicas privadas y, sobre todo, por el hecho de que la valoración del sistema sanitario público era relativamente baja hacia 1996 en toda España, situación que cambia a mejor a partir de ese año.

El ciudadano confirma su creencia en la mejor gestión de la empresa privada cuando compara las empresas públicas con las privadas. A éstas les asigna una mejor posición en la preparación de sus directivos, en rentabilidad, en eficacia y en mejor trato a los clientes, mientras que las públicas destacan porque tratan mejor a sus empleados. En la cuestión retributiva declaran que están casi a la par (CIS 1996. Estudio 2.224).

El funcionario es consciente de esta situación al considerar que su trabajo en la Administración pública está mayoritariamente peor valorado que trabajar en la empresa privada (CIS 1988. Estudio 1.741; 1990. Estudio 1.878). El efecto causado es el reforzamiento de su sentimiento de «falta de estima personal; vergüenza y frustración profesional» (González 2001. Estudio 66). Llevarían así razón los ciudadanos en que los funcionarios se encuentran menos motivados que los trabajadores del sector privado.

La conclusión de los datos obtenidos es que los ciudadanos, y también los funcionarios, creen en la superioridad de la gestión privada sobre la pública y en que valoran mejor las empresas privadas que las públicas, en las que incluyen genéricamente todas las formas de Administración pública, aunque esta superioridad no se manifieste siempre cuando se trata de servicios públicos concretos. La aceptación por las autoridades políticas de esta creencia no deja de tener importantes consecuencias en la elección de las estrategias llevadas a cabo para mejorar la eficacia del sistema político. Ante esta situación, los postulados de la NGP y de la calidad, por ejemplo, ganan legitimidad.

\section{El contraste teórico de la supuesta superioridad de lo privado}

La imagen negativa que los ciudadanos tienen de su Administración pública contrasta con la que comúnmente asignan a las empresas privadas. Esto no significa que, tomado servicio a servicio o empresa a empresa, los ciudadanos no les atribuyan unos defectos muy similares a los de las organizaciones y servicios públicos. Esto es probable que sea especialmente cierto en el caso de las grandes empresas, y concretamente las que tienen reglamentadas más detalladamente la relación con sus clientes, debido a que éstos tienen una vinculación más estable en el tiempo, como sucede con los bancos o las aseguradoras, entre otras. Al fin y al cabo, como señalaba Weber, ambos tipos de organizaciones son burocráticas. 
$\mathrm{Si}$, a pesar de que en la realidad diaria se constatan ineficacias, disfuncionalidades, ralentizaciones en los trámites y desmotivación en los trabajadores privados, se sigue creyendo en la superioridad de lo privado sobre lo público, puede deberse a que este tipo de comportamientos son minoritarios o a otro tipo de razones que afectan a la percepción que el ciudadano tiene de su Administración pública.

Nueve de cada diez ciudadanos consideran que existe un estereotipo social negativo sobre la Administración pública y que, como hemos visto, afecta incluso a los propios funcionarios. Sin embargo, un estudio más profundo de esa consideración muestra que los ciudadanos desde la óptica de contribuyente apuntan, entre otras, como razones de la imagen negativa de la Administración: que los tiempos cambian pero no la mentalidad y las actitudes en la política; que el estereotipo existe por las irregularidades que se mantienen, y que no resuelven nuestras demandas como contribuyentes (González 2001: 76-7).

Se confirmaría así que el origen de los problemas y, consecuentemente, de las soluciones a la mala imagen de la Administración caen en el campo de la política y no en el de la gestión. Si hacemos la traducción de esas explicaciones al campo privado, veremos que si la respuesta de los clientes ante los no excepcionales casos de corrupción en las grandes empresas se saldase con la no exigencia de responsabilidades a sus más altos directivos, y no se emitiese una señal clara por parte de una empresa afectada hacia sus clientes y el mercado de que se iba a producir un drástico cambio en el estilo de hacer negocios, el cierre de la empresa afectada estaría probablemente próximo. El refuerzo ético y de la transparencia de las empresas y la creación de códigos éticos o deontológicos de actuación, tan de moda en la actualidad, responden a esta realidad.

Los defensores del Estado o del mercado esgrimen numerosos argumentos para justificar el dominio de uno sobre el otro, pero no existen condiciones estructurales o criterios científicos que avalen con seriedad dichos argumentos. Las dos instituciones son logros culturales que han tenido históricamente como misión organizar la solución de las necesidades reales o sentidas del ser humano. No existiendo razones objetivas para justificar la bondad o maldad de cada uno de ellos, sólo queda la ideología teñida más o menos de construcción teológica (Beltrán 2000: 80).

Pero es cuestión bien diferente que no existan razones para imponer el Estado o el mercado a que el papel de ambos no sea bien diferente y que el del primero sea de una naturaleza cualitativa e históricamente superior. En primer lugar, las Administraciones públicas de los Estados modernos son anteriores a las empresas privadas y éstas son las que están en función del primero y no a la inversa (Baena 2000: 29). Segundo, el capitalismo de mercado sólo es posible en un país democrático con la intervención y la regulación estatal, ya que el mercado exige una amplia regulación e intervención estatal; sin éstas «se producen inevitablemente serios daños a determinadas personas» (Dahl 1999: 196). Tercero, la reforma o modernización de la Administración pública es condición para profundizar en el bienestar colectivo y en la democracia (Villoria 1996: 26), de ahí que tenga sentido afirmar que «reformar la Administración supone reformar la sociedad» (Baena 2000: 276). Cuarto, las organizaciones públicas son indispensables para la existencia de la sociedad, a la que vertebran (Baena 2000: 29). Y quinto, el Estado es un factor decisivo en el proceso general de la innovación tecnológica (Castells 1997: 38-9).

Desde una perspectiva ajena al funcionamiento real del poder público podría pensarse que los movimientos a favor del mercado, y muy singularmente la NGP, han hecho retroceder la importancia del Estado y su propia presencia en la sociedad. Sin embargo, lo que probablemente se ha producido es una adaptación a las nuevas condiciones económicas y culturales. Su dominio sobre el mercado se realza de una manera menos intervencionista, pero es dudoso que sea menos profunda que en etapas anteriores. La externalización de servicios, la extensión de la participación, la descentralización o ciertas modalidades de devolución de poderes a la sociedad no suponen por sí mismas una retirada del Estado en favor de la sociedad, sino que en muchas ocasiones son nue- 
vas vías de penetración, articulación y vertebración de la sociedad por parte del Estado a través de las Administraciones públicas, ya que éstas no pierden el control completo sobre las actividades públicas. Además, éstas se suelen mezclar con actividades que eran propias del mundo privado o del mercado, pero que a través de las nuevas técnicas de gestión y de intervención se vinculan con mayor o menor intensidad a lo público.

Entre los nuevos valores que los gobiernos han ido introduciendo en la cultura política y en la cultura cívica está la competitividad, y ésta ha actuado como confirmadora de la superioridad del mercado sobre el Estado. La competitividad se ha convertido en un valor social aceptado y compartido de forma generalizada, en un sello distintivo de la forma de actuar de los individuos en nuestra sociedad. A su logro se han aplicado con gran intensidad las instituciones políticas con el fin de generar altos niveles de renta en sus sociedades. La competitividad sería una «bandera» de los gobiernos, frente a la rentabilidad que sería propia de las empresas, y ambas son las «determinantes reales de la innovación tecnológica y el crecimiento de la productividad» (Castells 1997: 107 y ss.).

Los efectos de abrazar un nuevo principio explicativo de la realidad social desde la economía son directos. Los ciudadanos pasan a contemplar de manera distinta su papel en la vida en comunidad. Ésta poco a poco se individualiza e informaliza al articularse por principios más laxos que los propios de un Estado con prescripciones fuertes jurídicas y políticas y, por tanto, reconducibles formalmente a un centro de responsabilidad. Es cierto que ahora al ciudadano se le ofrecen numerosos cauces para obtener y exigir ésta, pero también lo es que pocos disponen de tiempo, interés, conocimientos y recursos necesarios, y que los objetivos a conseguir son ahora más difusos (Olías de Lima 2001: 25).

La creencia en la superioridad del mercado se puede ver fortalecida porque no se ha tenido éxito en introducir el principio de la competitividad en la Administración pública en su forma de «mercado público», ya que el ciudadano sigue atribuyendo este principio predominantemente al sector privado. Así, en 1992, el 52,9 por cien de los ciudadanos españoles entrevistados atribuían la competitividad a éste, frente a un 11,1 que lo hacía al sector público (CIS 1992. Estudio 2.019).

El fracaso de los gobiernos en introducir la competitividad en sus Administraciones públicas puede estar justificado. Las resistencias detectadas en los funcionarios al cambio y la modernización son ciertas (CIS 1988: 1.741; CIS 1990: 1.878; Ramió 1999: 210; ESDEM 2000), pero también pueden ser vistas como manifestación de un choque entre valores que se pueden personalizar en la competitividad y la equidad social. La primera puede ir en detrimento de la segunda, por lo que es posible entender que los funcionarios educados en una cultura orientada a satisfacer al interés general puedan resistirse a aceptar y hacer suyo un principio que puede destacar lo individual sobre lo colectivo.

Los ciudadanos parecen opinar de la misma manera, ya que el único atributo positivo que asignan a lo público frente a la empresa privada es precisamente la equidad social, un 58 por cien frente a un 10,6, respectivamente (CIS 1988. Estudio 1.741; CIS 1990. Estudio 1.878). Por otra parte, nada se pregunta en los estudios realizados sobre la ponderación que cada uno de esos principios tiene en los valores de los ciudadanos en relación con la Administración pública o con los principios que deben articular la sociedad. Sólo conocemos que el 58 por cien de los españoles declaraban que era más importante para ellos la igualdad social, frente a un 21 que declaraba que preferían la libertad individual (CIS 2000. Estudio 2401). En fin, es probable que la mayoría estemos de acuerdo en que la igualdad social es un objetivo propio de lo público más que del mercado.

Es posible que cuando los ciudadanos señalen la «falta de mentalidad empresarial en la Administración pública» se refieran a cuestiones relacionadas con la eficiente utilización de sus impuestos más que a que deseen 
una alteración profunda de los criterios públicos de asignación de recursos, o de acceso a las prestaciones públicas. Ninguno de esos criterios tiene por qué coincidir con los de las empresas comerciales (Beltrán 2000: 92). A esto parece responder el deseo de los ciudadanos de que los gestores de los recursos públicos sean «efectivos socialmente» en sus actuaciones y de que el uso de los fondos públicos produzca una «utilidad social», mayor que la que la propia sociedad pudiera obtener por sí misma (González 2001: 140-2; D’Amico 1992: 403).

Por último, puede darse la paradoja de que la introducción de criterios propios de la empresa privada en algunas organizaciones que gestionan fines públicos logre la efectividad que tanto se busca, pero a costa del reconocimiento y validación ciudadana de la institución política y de sus integrantes, porque el ciudadano no pueda adscribir los éxitos de dichas organizaciones a éstos. Este sería el caso de determinadas agencias y empresas públicas que de tanto intentar no ser incluidas en el ámbito público burocrático y funcionarial consiguen que sus triunfos, de haberlos, no sean atribuidos al gobierno que las financia.

\section{REFERENCIAS BIBLIOGRÁFICAS}

Alba C.R. y Vanaclocha, F.J (1997), El sistema politico local: un nuevo escenario de Gobierno. Madrid: BOE / Universidad Carlos III.

Almond, G. A. (1999), «La historia intelectual del concepto de cultura cívica», en R. del Águila y F. Vallespín, eds., La democracia en sus textos. Madrid: Alianza.

Alvira F., García, J., y Delgado, M. (2000), Sociedad, impuestos y gasto público. La perspectiva del contribuyente. Madrid: CIS.

Baena M. (2000), Curso de Ciencia de la Administración. I. Madrid: Tecnos.

Beltrán, M. (2000), La acción pública en el régimen democrático. Madrid: Centro de Estudios Políticos y Constitucionales.

Botella, J. Coord (1999), La ciudad democrática. Barcelona: Ediciones del Serbal.

Brugué, J., Gallego, R. (2001), «¿Una Administración pública democrática?», en J. Font ed., Ciudadanos y decisiones públicas. Barcelona: Ariel.

Castresana, J. I. y Blanco, A. (2000), Liderazgo total en la empresa. Granada: CEMCI.

Christensen, T. y Peters, G. (1999), Structure, Culture, and Governance. Rowman \& Littlefield Publishers Inc. Lanham

CIS (2000), Estado de las Autonomías: Balance de las instituciones autonómicas en España, 1980-2000. Informe final 25 de junio de 2000, Niche Consulting S.L. para el CIS (mimeografiado).

- (1997), Informe metodológico y principales resultados del estudio sociológico cualitativo sobre «Coyuntura de opinión sociopolitica en España».

Para CIS Estudio n. ${ }^{\circ} 2243$. Eco Consulting. Abril.

- (1994), Imágenes dominantes en el discurso social. E 2086. CIS. Febrero. INMARK Estudios y estrategias S. A.

D’Amico D. (1992), Manuale di scienza dell'amministrazione. Roma: Edizioni Lavoro.

Dahl, R. (1999), La democracia: una guía para los ciudadanos. Madrid: Taurus.

De Miguel, I. y De Miguel, A. (2001), «Los españoles y los impuestos», Opiniones y actitudes 35.

Dienel, P.C. y Harms, H. (2000), Repensar la democracia. Los Núcleos de Intervención Participativa. Barcelona: Ediciones del Serbal.

ESDEM (2000), Estudio de imagen y valoración de los servicios de información del Gobierno de La Rioja.

Font, J. Ed. (2001), Ciudadanos y decisiones públicas. Barcelona: Ariel.

Frías, S. M. (2001), «Cultura política en España: conocimiento, actitudes y práctica». Opiniones y actitudes 39.

González, A. (2001), Claves de valoración a nivel operativo de la Comunidad Autónoma de La Rioja. AG-EMVIS Management, mimeografiado. 
García de la Cruz Herrero, J. J. (1995), «La defensa de intereses ante las autoridades públicas. ¿Acción colectiva o acción individual?», Reis 69: 39-68.

Gomá, R. y Subirats, J., eds (1998), Politicas públicas en España. Barcelona: Ariel.

González, F. (1994 [1840]), Elementos de Ciencia Administrativa. Santafé de Bogotá: Escuela Superior de Administración Pública.

Gualteri, R. (1999), Impact of the Emerging Information Society on the Policy Development Process and Democratic Quality. <OCDE-PUMA www.oecd.org/puma/>.

Informe Nolan (1995), Standards in Public Life. First Report of the Committee on Standards in Public Life, 1. HMSO: London.

Inglehart, R. (1998), Modernización y postmodernización. El cambio cultural, económico y politico en 43 sociedades. Madrid: CIS.

Jerez, A., Sampedro, V. y Baer, A. (2000), Medios de comunicación, consumo informativo y actitudes politicas en España. Madrid: CIS.

Kaufmann, A. (1997), «Liderazgo transformador y formación continua». Revista Española de Investigaciones Sociológicas 77-78: 163184.

Keating, M. (1997), «Managing for Results in the Public Interest», en M. Considine y M. Painter, eds., Managerialism: The Great Debate. Melbourne: Melbourne University Press.

Lijphart, A. (2000), Modelos de democracia. Barcelona: Ariel.

Llorens, F. J. y Fuentes, M. (2000), Calidad total. Fundamentos e implantación. Madrid: Pirámide.

Llera, F. J. (1997), «Enfoques en el estudio de la cultura política», en P. Castillo e I. Crespo, eds., Cultura politica. Valencia: Tirant lo Blanch.

Offe, C. (1990), Contradictions of the Welfare State. Londres: Hutchinson.

Olías de Lima, B. Coord., (2001), La nueva gestión pública. Madrid: Pearson Educación S.A.

Parrado, S. (2001), «El liderazgo y la gestión directiva en las organizaciones públicas: el estado de la cuestión», en B. Olías de Lima, coord., La nueva gestión pública. Madrid: Pearson Educación S.A.

Pérez, E. (2002), ¿Cómo se promueve y legisla la participación del voluntariado social en Andalucia? VII Congreso Internacional del CLAD sobre la Reforma del Estado y de la Administración Pública. Lisboa.

Pollit, Ch. (1995), «Management Techniques for the Public Sector: Pulpit and Practice» en B. G. Peters, y D. J. Savoie eds., (1995), Governance in a Changing Environment. Montreal y Kingston: Canadian Centre for Management Development, McGillQuenn's University Press.

Ramió, C. (1999), Teoría de la Organización y Administración Pública. Madrid: Tecnos / Universitat Pompeu Fabra.

Román, L. (2001), «La cultura organizativa y la ética pública» en B. Olías de Lima, coord., La nueva gestión pública. Madrid: Pearson Educación S.A.

Sánchez-Cuenca, I. y Barreiro, B. (2000), Los efectos de la acción de gobierno en el voto durante la etapa socialista (1982-1996). Madrid: CIS.

Vilas, J. (2000), «Sentimientos hacia la política: una discusión, con alguna ilustración empírica», Revista de Estudios Politicos (Nueva Época) 108.

Villoria, M. (1996), La modernización de la Administración como instrumento al servicio de la democracia. Madrid: MAP-BOE.

Wildawsky, A. (1987), «A Cultural theory of responsability», en Lane, ed., Bureaucracy and public choice. Londres: Sage.

\section{Fuentes documentales. Estudios del CIS}

1979: 1.191. Gasto Público.

1988: 1.741. Funcionarios y contratados laborales.

1989: 1.848. Los servicios de información administrativa. 
1990: 1.878. Funcionarios Públicos (II).

1990: 1.901. Barómetro de octubre 1990

1992: 2.019. Servicios Públicos.

1993: 2.054. Imagen social de los funcionarios.

1995: 2.186. Barómetro sobre el sistema sanitario 1995.

1995: 2.187. Opinión pública y Política Fiscal (XII).

1996: 2.212. Barómetro de abril 1996.

1996: 2.219. Opinión pública y Política Fiscal (XIII).

1996: 2.224. Economía y sociedad: cultura económica.

1997: 2.253. Opinión pública y Política Fiscal (XIV).

1999: 2.318. Barómetro sanitario, 1999 (primera oleada).

1999: 2.364. Barómetro de junio de 1999.

2000: 2.387. Barómetro de marzo de 200. Cultura política.

2000: 2.394. Barómetro de junio de 2000.

2000: 2.401. 25 años después.

2001: 2.419. Barómetro de mayo 2001

2002: 2.462. Opinión pública y política fiscal (XIX).

Datos de opinión 1, 2, 3, 5 y 14. Series históricas del CIS.

CIS Opiniones y actitudes n. ${ }^{\circ} 29$

Series temporales del CIS. 